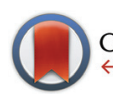

CrossMark

Cite this: Dalton Trans., 2016, 45 5162

Received 21st December 2015, Accepted 3rd February 2016

DOI: $10.1039 / \mathrm{c} 5 \mathrm{dt} 04963 f$

www.rsc.org/dalton

\title{
Extraction and coordination studies of a carbonyl- phosphine oxide scorpionate ligand with uranyl and lanthanide(III) nitrates: structural, spectroscopic and DFT characterization of the complexes $\uparrow$
}

\author{
Anna G. Matveeva, ${ }^{* a}$ Anna V. Vologzhanina, ${ }^{a}$ Evgenii I. Goryunov, ${ }^{a}$ Rinat R. Aysin, ${ }^{a}$ \\ Margarita P. Pasechnik, ${ }^{a}$ Sergey V. Matveev, ${ }^{a}$ Ivan A. Godovikov, ${ }^{a}$ Alfiya M. Safiulina ${ }^{b}$ \\ and Valery K. Brela
}

\begin{abstract}
Hybrid scorpionate ligand $(\mathrm{OPPh})_{2} \mathrm{CHCH}_{2} \mathrm{C}(\mathrm{O}) \mathrm{Me}(\mathrm{L})$ was synthesized and characterized by spectroscopic methods and X-ray diffraction. The selected coordination chemistry of $\mathrm{L}$ with $\cup_{2}\left(\mathrm{NO}_{3}\right)_{2}$ and $\mathrm{Ln}\left(\mathrm{NO}_{3}\right)_{3}(\mathrm{Ln}=\mathrm{La}, \mathrm{Nd}, \mathrm{Lu})$ has been evaluated. The isolated mono- and binuclear complexes, namely, $\left[\mathrm{UO}_{2}\left(\mathrm{NO}_{3}\right)_{2} \mathrm{~L}\right]$ (1), $\left[\left\{\mathrm{UO}_{2}\left(\mathrm{NO}_{3}\right) \mathrm{L}\right\}_{2}\left(\mu_{2}-\mathrm{O}_{2}\right)\right] \cdot \mathrm{EtOH}(\mathbf{2}),\left[\mathrm{La}\left(\mathrm{NO}_{3}\right)_{3} \mathrm{~L}_{2}\right] \cdot 2.33 \mathrm{MeCN}$ (3), $\left[\mathrm{Nd}\left(\mathrm{NO}_{3}\right)_{3} \mathrm{~L}_{2}\right] \cdot 3 \mathrm{MeCN}(4),\left[\mathrm{Nd}\left(\mathrm{NO}_{3}\right)_{2} \mathrm{~L}_{2}\right]^{+} \cdot\left(\mathrm{NO}_{3}\right)^{-} \cdot \mathrm{EtOH}(5)$ and $\left[\mathrm{Lu}\left(\mathrm{NO}_{3}\right)_{3} \mathrm{~L}_{2}\right](6)$ have been characterized by IR spectroscopy and elemental analysis. Single-crystal X-ray structures have been determined for complexes $1-5$. Intramolecular intraligand $\pi$-stacking interactions between two phenyl fragments of the coordinated ligand(s) were observed in all complexes $\mathbf{1 - 5}$. The $\pi$-stacking interaction energy was estimated from Bader's AIM theory calculations performed at the DFT level. Solution properties have been examined using IR and multinuclear $\left({ }^{1} \mathrm{H},{ }^{13} \mathrm{C}\right.$, and $\left.{ }^{31} \mathrm{P}\right) \mathrm{NMR}$ spectroscopy in $\mathrm{CD}_{3} \mathrm{CN}$ and $\mathrm{CDCl}_{3}$. Coordination modes of $\mathbf{L}$ vary with the coordination polyhedron of the metal and solvent nature showing many coordination modes: $\mathrm{P}(\mathrm{O}), \mathrm{P}(\mathrm{O}), \mathrm{P}(\mathrm{O}), \mathrm{P}(\mathrm{O}), \mathrm{C}(\mathrm{O}), \mathrm{P}(\mathrm{O}), \mathrm{C}(\mathrm{O})$, and $\mathrm{P}(\mathrm{O})$. Preliminary extraction studies of $\mathrm{U}(\mathrm{VI})$ and $\mathrm{Ln}(\mathrm{III})(\mathrm{Ln}=\mathrm{La}, \mathrm{Nd}, \mathrm{Ho}, \mathrm{Yb})$ from $3.75 \mathrm{M} \mathrm{HNO}_{3}$ into $\mathrm{CHCl}_{3}$ show that scorpionate $\mathrm{L}$ extracts $\mathrm{f}$-block elements (especially uranium) better than its unmodified prototype $(\mathrm{OPPh})_{2} \mathrm{CH}_{2}$.
\end{abstract}

\section{Introduction}

Bidentate neutral organophosphorus extractants, first of all phosphine oxides (carbamoylphosphine oxides, alkylenediphosphine dioxides), are the most efficient extractants for the recovery of transplutonium, rare earth, and other elements from the waste of spent nuclear fuel reprocessing, to recover different metals from processing solutions of hydrometallurgy and to design analytical test objects for the same metals. ${ }^{1-4}$ These compounds are also important in medicine for the dia-

\footnotetext{
${ }^{a}$ Nesmeyanov Institute of Organoelement Compounds, Russian Academy of Sciences, 28 Vavilov Str., Moscow 119991, Russia

${ }^{b}$ OJSC United Chemical Company Uralchem, Presnenskaya nab. 6/2, Moscow, 123317 Russia.E-mail: matveeva@ineos.ac.ru; Fax: +7-4991355085; Tel: $+7-4991359366$

$\dagger$ Electronic supplementary information (ESI) available: Selected IR data for complexes 1, 3-6, X-ray data for compounds L, 1-5, selected NMR spectra for compounds $\mathbf{L}, \mathbf{1}, 3, \mathbf{6}$, and extraction data for $\mathbf{L}$ and $\mathbf{L}^{\prime}$. CCDC 1442097-1442102. For ESI and crystallographic data in CIF or other electronic format see DOI: 10.1039/ c5dt04963f
}

gnosis and treatment of different pathologies, mainly affecting the locomotor apparatus. The design of novel functionalized phosphine oxides showing higher efficiency and selectivity is one of the major and topical fields of extractive and synthetic chemistry.

Thus, highly efficient extractants for the recovery of actinides and rare earth elements from nitric acid solutions were found among derivatives of methylenediphosphine dioxide ${ }^{2-5}$ [Scheme 1(a) and (b)]. This fact favored the development of the coordination chemistry of these ligands, in particular their ability to coordinate ions of f-block elements. ${ }^{6-8}$

The introduction of $\mathrm{Ar}_{2} \mathrm{P}(\mathrm{O}) \mathrm{CH}_{2}$ and $\mathrm{Ar}_{2} \mathrm{PCH}_{2}$ functional groups showing coordination ability into the methylene bridge of dioxide [Scheme 1, (a)] leads to new scorpionate ligands [Scheme 1, (c)-(d),)] that are promising extractants for nuclear fuel reprocessing. ${ }^{9}$ All strongly donating $\operatorname{Ar}_{2} \mathrm{P}(\mathrm{O})$ and $\mathrm{Ar}_{2} \mathrm{P}$ groups of these scorpionates, as expected, participate in coordination to lanthanide-like $\mathrm{Y}(\mathrm{III}) .{ }^{9}$ The coordination properties of such a scorpionate ligand change considerably if the donor phosphorus-containing group in substituent 


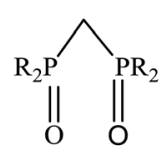

(a)

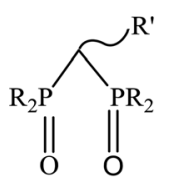

(b)

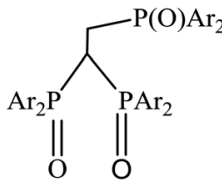

(c)

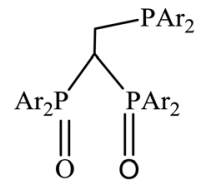

(d)

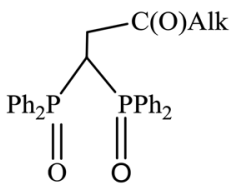

(e)

$\mathrm{R}=\mathrm{Ar}, \mathrm{Alk}, \mathrm{AlkO} \quad \mathrm{R}^{\prime}=\mathrm{Alk}, \mathrm{Ar}, \mathrm{CH}_{2} \mathrm{X}$

Scheme 1 Structures of different types of ligands bearing $>\mathrm{P}(\mathrm{O}) \mathrm{CH}_{2} \mathrm{P}(\mathrm{O})<$.

$\mathrm{Ar}_{2} \mathrm{P}(\mathrm{O}) \mathrm{CH}_{2}{ }^{-}, \mathrm{Ar}_{2} \mathrm{PCH}_{2^{-}}$is replaced by a less basic $\mathrm{AlkC}(\mathrm{O})-$ group [Scheme 1, (e)]. Less basic carbonyl groups may not form coordination bonds with cations or form weaker bonds than phosphorus functionalities, as well as participate in other weak interactions. Consequently, such a modification can considerably change not only coordination, but also the extractive properties of the ligand.

In this paper, we report the modified synthesis of a scorpionate ligand $\left[\mathrm{Ph}_{2} \mathrm{P}(\mathrm{O})\right]_{2} \mathrm{CHCH}_{2} \mathrm{C}(\mathrm{O}) \mathrm{Me}(\mathbf{L})$ and its new complexes with uranyl and lanthanide(III) nitrates, the structural characterization of all compounds in the solid state (X-ray crystallography for L, 1-5) and in solution by IR and multinuclear NMR $\left({ }^{1} \mathrm{H},{ }^{13} \mathrm{C},{ }^{31} \mathrm{P}\right)$ spectroscopy, and extraction studies towards the f-block elements. Furthermore, we report herein the results of AIM analysis (Bader's "Atoms in molecules" approach) for the $\pi$-stacking interactions in the $\mathrm{U}(\mathrm{VI}), \mathrm{La}(\mathrm{III})$, and $\mathrm{Nd}(\mathrm{III})$ complexes. Extraction ability of ligand $\mathbf{L}$ for the recovery of $\mathrm{U}(\mathrm{VI})$ and $\mathrm{Ln}(\mathrm{III})$ from nitric acid solution into chloroform in comparison with the $\mathrm{Ph}_{2} \mathrm{P}(\mathrm{O}) \mathrm{CH}_{2} \mathrm{P}(\mathrm{O}) \mathrm{Ph}_{2}\left(\mathbf{L}^{\prime}\right)$ prototype was evaluated.

\section{Results and discussion}

\subsection{Synthesis and characterization of the ligand $L$}

We prepared compound $\mathbf{L}$ via a modified variant ${ }^{10}$ of the Conant reaction ${ }^{11}$ that consists of combining $\mathrm{Ph}_{2} \mathrm{PCl}$ with $(E)$ 4-(diphenylphosphoryl)but-3-en-2-one, we developed the synthesis of the latter earlier. ${ }^{12}$ The reaction was conducted in anhydrous acetonitrile solution at ambient temperature with the addition of acetic acid (Scheme 2). Under these conditions, the reaction was completed over $48 \mathrm{~h}$ to give 4,4-bis(diphenylphosphoryl)butan-2-one (L) in 90\% yield (according to ${ }^{31} \mathrm{P}\left\{{ }^{1} \mathrm{H}\right\}$ NMR spectra of the reaction mixture). It should be noted that this is the first example of the successful use of the Conant reaction for the synthesis of gem-diphosphoryl-substituted alkanones.

The ligand $\mathbf{L}$ has been characterized by elemental analysis, IR, ${ }^{1} \mathrm{H},{ }^{31} \mathrm{P}\left\{{ }^{1} \mathrm{H}\right\}$, and ${ }^{13} \mathrm{C}$ NMR spectroscopy. Thus, in particular, the ${ }^{1} \mathrm{H}$ NMR spectrum of this compound, whose molecule contains two identical diphenylphosphoryl groups, shows the proton signals of the $\mathrm{CH}_{2}$ and $\mathrm{CH}$ groups as a doublet of triplets and triplet of triplets, respectively, which transform into a doublet and triplet under broad band ${ }^{1} \mathrm{H}^{3}{ }^{31} \mathrm{P}$ decoupling $\left({ }^{1} \mathrm{H}\left\{{ }^{31} \mathrm{P}\right\}\right.$ NMR spectrum). The ${ }^{13} \mathrm{C}\left\{{ }^{1} \mathrm{H}\right\}$ NMR spectrum also shows triplets of $\mathrm{C}=\mathrm{O}$ and $\mathrm{CH}$ carbon atoms due to spin-spin coupling with the phosphorus nuclei of two $\mathrm{Ph}_{2} \mathrm{P}(\mathrm{O})$ groups. The IR spectrum of a crystalline sample of $\mathbf{L}$ exhibits $\nu(\mathrm{P}=\mathrm{O})$ bands at 1202 and $1182 \mathrm{~cm}^{-1}$ and a $\nu(\mathrm{C}=\mathrm{O})$ band at $1720 \mathrm{~cm}^{-1}$. The DFT computational data for the normal vibration frequencies of ligand $\mathbf{L}$ agree well with the experimental values without any scaling. ${ }^{13}$

In addition to spectral experiments, compound $\mathbf{L}$ was characterized in the solid state using single-crystal X-ray diffraction. Scorpionate ligand $\mathbf{L}$ displays typical bond lengths and angles, with the oxygen atoms of the phosphoryl groups trans-situated with respect to the C13 atom (Fig. 1). Selected bond distances are given in Table 1 . Such a conformation of $\mathbf{L}$ is additionally stabilized with $\pi$-stacking between the phenyl groups of different phosphorus functionalities (the centroidcentroid distance is equal to 3.681(2) $\AA$ and the dihedral angle between the ring planes is equal to $\left.10.81(8)^{\circ}\right)$. Thus, the realization of a bi- and tridentate coordination mode for this ligand requires the rotation of donor arms as compared with its conformation in the solid state. All three donor groups are involved in weak intra- and intermolecular $\mathrm{C}-\mathrm{H} \cdots \mathrm{O}$ interactions. Intermolecular $\mathrm{C}_{\mathrm{Ph}}-\mathrm{H} \cdots \mathrm{O}$ contacts are the most significant. The shortest $r(\mathrm{H} \cdots \mathrm{O})$ distances are $2.60 \AA$ for the carbonyl group, 2.28, $2.38 \AA$ (for P1-O1) and 2.46, $2.62 \AA$ (for $\mathrm{P} 2-\mathrm{O} 2)$ for the phosphoryl groups (Fig. S1, ESI $\dagger$ ).
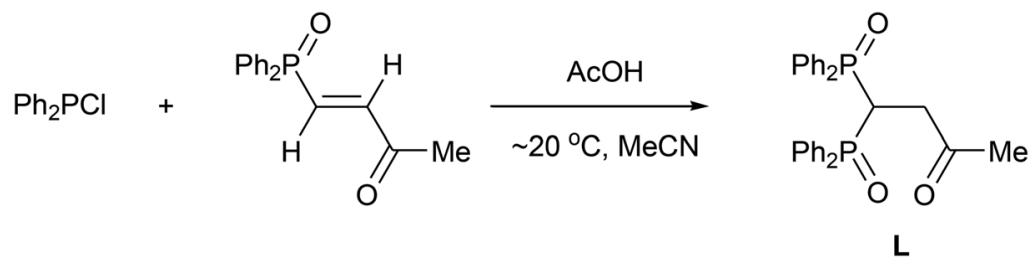

Scheme 2 Synthesis of 4,4-bis(diphenylphosphoryl)butan-2-one (L). 


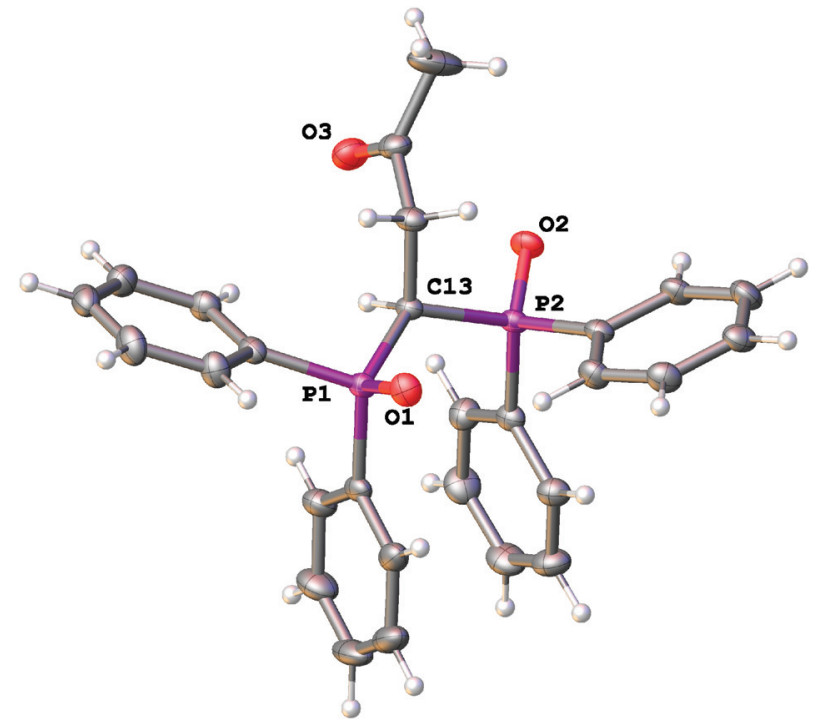

Fig. 1 General view of $\mathrm{L}$ with the atoms represented as thermal ellipsoids drawn at $p=50 \%$.

Table 1 Selected bond distances ( $(\AA)$ in $L$, and uranyl complexes 1 and 2

\begin{tabular}{llll}
\hline Bond & L & 1 & 2 \\
\hline $\mathrm{P} 1=\mathrm{O} 1$ & $1.485(1)$ & $1.500(2)$ & $1.487(6)$ \\
$\mathrm{P} 2=\mathrm{O} 2$ & $1.493(1)$ & $1.503(2)$ & $1.495(6)$ \\
$\mathrm{C}=\mathrm{O}$ & $1.208(2)$ & $1.213(4)$ & $1.202(12)$ \\
$\mathrm{U} 1=\mathrm{O} 1$ & & $1.761(2)$ & $1.877(11)$ \\
$\mathrm{U} 1=\mathrm{O} 2$ & & $1.760(2)$ & $1.658(12)$ \\
$\mathrm{U} 1-\mathrm{O} 3(\mathrm{~L}) / \mathrm{O} 9(\mathrm{~L})$ & & $2.393(2)$ & $2.397(6)$ \\
$\mathrm{U} 1-\mathrm{O} 4(\mathrm{~L}) / \mathrm{O} 8(\mathrm{~L})$ & & $2.398(2)$ & $2.463(6)$ \\
$\mathrm{U} 1-\mathrm{O}($ nitrate) & & $2.506(3)-2.540(3)$ & $2.520(7)-2.549(7)$ \\
$\mathrm{U} 1-\mathrm{O}$ (peroxo) & & & $2.361(12)-2.407(12)$
\end{tabular}

As far as we know, compound $\mathbf{L}$ is the first example of a hybrid scorpionate ligand combining two $\mathrm{P}(\mathrm{O})$ and one $\mathrm{C}(\mathrm{O})$ side arms that has ever been characterized in the solid state.

\subsection{Synthesis and solid state characterization of the complexes}

Compound $\mathbf{L}$ is a hybrid scorpionate ligand with a combination of two phosphoryl and one carbonyl groups. Therefore the coordination behavior of this ligand is interesting since the free rotation of donor arms can give a different possible combination of coordination modes. Various possible coordination modes of $\mathbf{L}$, as depicted in Scheme 3, can be observed for mononuclear complexes.

$\mathrm{C}(\mathrm{O})$-Monodentate coordination is the least probable (not shown in the Scheme). Obviously, the metal and the composition of the complex affect the choice of coordination mode. The fblock element coordination chemistry of this scorpionate ligand was studied in order to understand its coordination behavior.

Mononuclear complex $\left[\mathrm{UO}_{2}(\mathbf{L})\left(\mathrm{NO}_{3}\right)_{2}\right]$ (1) was prepared by addition of 1 equivalent of $\mathrm{UO}_{2}\left(\mathrm{NO}_{3}\right)_{2} \cdot\left(\mathrm{H}_{2} \mathrm{O}\right)_{6}$ in acetonitrile to 1 equivalent of compound $\mathbf{L}$ in chloroform to form a bright yellow microcrystalline powder. Crystallization of an ethanolic solution of $\mathbf{1}$ when exposed to sunlight yielded a trace amount of a yellow product with structural analyses consistent with the formula $\left[\left\{\mathrm{UO}_{2}\left(\mathrm{NO}_{3}\right) \mathbf{L}\right\}_{2}\left(\mu_{2}-\mathrm{O}_{2}\right)\right] \cdot \mathrm{EtOH}(2)$. The appearance of the bidentate peroxo $\left[\mathrm{O}_{2}\right]^{2-}$ anion in uranyl nitrate solutions in the presence of atmospheric dioxygen is possible due to the sunlight photolysis of EtOH. ${ }^{14}$ The mechanism of this photolysis has been previously reported. ${ }^{15}$

Mononuclear bisligand complexes $\left[\mathrm{La}\left(\mathrm{NO}_{3}\right)_{3} \mathbf{L}_{2}\right] \cdot 2.33 \mathrm{MeCN}$ (3), $\left[\mathrm{Nd}\left(\mathrm{NO}_{3}\right)_{3} \mathbf{L}_{2}\right] \cdot 3 \mathrm{MeCN}(\mathbf{4}),\left[\mathrm{Nd}\left(\mathrm{NO}_{3}\right)_{2} \mathbf{L}_{2}\right] \cdot\left(\mathrm{NO}_{3}\right) \cdot \mathrm{EtOH}(\mathbf{5})$ and $\left[\mathrm{Lu}\left(\mathrm{NO}_{3}\right)_{3} \mathbf{L}_{2}\right](\mathbf{6})$ isolated in a pure state were obtained by combining stoichiometric amounts of the ligand and the salts in a mixture of aprotic solvents followed by crystallization from the corresponding solvent.

The composition and structures of the complexes in the solid state were studied using elemental analysis, and IR spectroscopy. The structures of the crystal complexes 1-5 were also elucidated by X-ray diffraction.

2.2.1. X-ray structures. According to the data of singlecrystal X-ray diffraction, compound $\mathbf{1}$ is a neutral mononuclear complex, where the uranium atom adopts a hexagonal bipyramidal geometry with one bidentate chelate ligand $\mathbf{L}$ and two bidentate nitrate anions situated in the equatorial plane and uranyl oxygen atoms in the apical positions (Fig. 2). The $\mathrm{C}=\mathrm{O}$ group is oriented in the opposite direction with respect to the uranium atom).

The absence of strong intermolecular interactions that involve the oxygen atoms of the uranyl group, results in its linearity (the O1-U1-O2 angle is equal to $\left.179.9(1)^{\circ}\right)$ and similarity of the $\mathrm{U}=\mathrm{O}$ distances $(1.760(2)$ and 1.761(2) $\mathrm{\AA})$ in 1. In complex

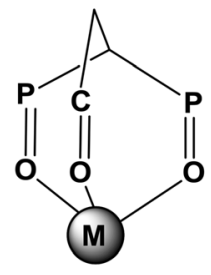

$\eta 3-$ mode<smiles></smiles><smiles></smiles>

$\eta 2-$ mode

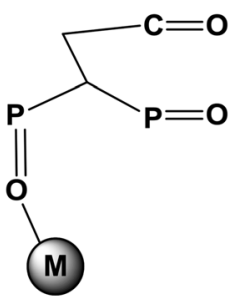

$\eta 1-$ mode

Scheme 3 Possible coordination modes of ligand L in mononuclear complexes. 


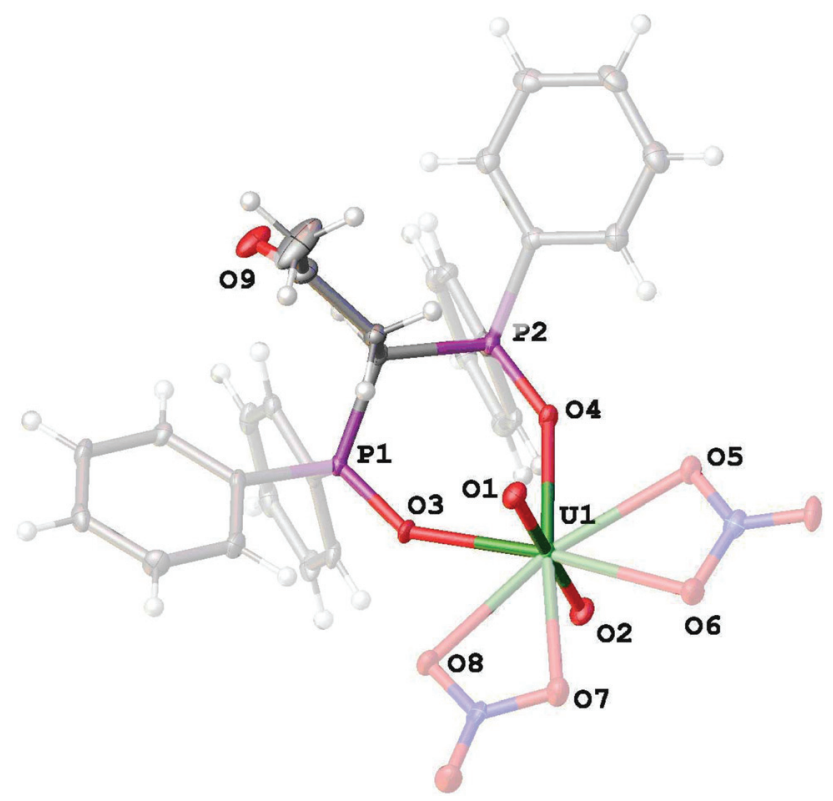

Fig. 2 General view of 1 with the atoms represented as thermal ellipsoids drawn at $p=50 \%$.

$\left[\mathrm{UO}_{2}\left(\mathrm{NO}_{3}\right)_{2} \mathbf{L}^{\prime}\right](7)^{7}$ (where $\mathbf{L}^{\prime}$ is $\mathrm{Ph}_{2} \mathrm{P}(\mathrm{O}) \mathrm{CH}_{2} \mathrm{P}(\mathrm{O}) \mathrm{Ph}_{2}$ ), which has a similar molecular structure to $\mathbf{1}$, the $\mathrm{U}=\mathrm{O}$ distances differ rather considerably, 1.781(11) and 1.768(11) $\AA$, due to the presence of intermolecular $\mathrm{C}-\mathrm{H} \cdots \mathrm{O} 1$ bonding. Complex 1 also involves intermolecular contacts $\mathrm{C}-\mathrm{H} \cdots \mathrm{O}=\mathrm{C}$, with $r(\mathrm{H} \cdots \mathrm{O})$ distances in them being virtually the same as in the structure of the ligand (Fig. S2, ESI $\dagger$ ).

Neutral dinuclear complex 2 (Fig. 3) contains only half of the complex in the asymmetric unit. $\mathbf{L}$ acts as a bidentate chelate $\mathrm{P}(\mathrm{O}), \mathrm{P}(\mathrm{O})$-ligand and the other equatorial positions of the uranium(vi) atom in $\mathbf{2}$ are occupied by the oxygen atoms of the bidentate chelate nitrate anion and the bridging bidentate peroxo anion.

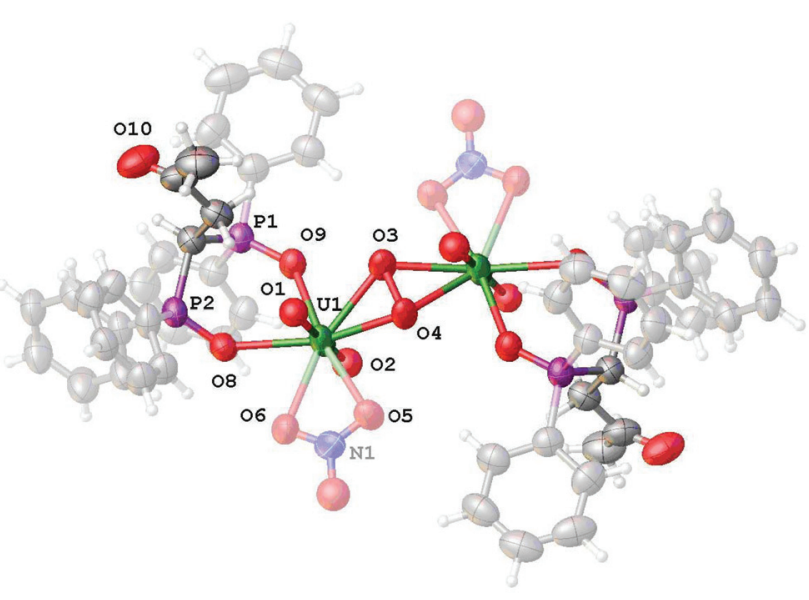

Fig. 3 General view of 2 with the atoms represented as thermal ellipsoids drawn at $p=50 \%$. Uranyl oxygen atoms, the peroxo group and an oxygen atom of the nitrate anion are disordered over two sites, and only one of the disordered components is depicted.
The resulting coordination polyhedron $\mathrm{UO}_{8}$ adopts a hexagonal bipyramidal geometry with the uranyl oxygen atoms in apical positions. Two nitrates (and two $\mathbf{L}$ ligands) are transsituated to each other with respect to the $\mathrm{UO}_{2} \mathrm{U}$ species as it was previously observed in complexes with a similar $\left[\left\{\mathrm{UO}_{2}\left(\mathrm{NO}_{3}\right) \mathrm{X}\right\}_{2}\left(\mu_{2}-\mathrm{O}_{2}\right)\right]$ composition, where $\mathrm{X}$ is the bidentate chelate neutral ligand $\left(\mathrm{X}=\right.$ tetraethylsuccinamide $,{ }^{16} 2,2^{\prime}$-bipyridy $1^{17}$ or $5,5^{\prime}$-dimethyl-2,2'-bipyridine $\left.{ }^{18}\right)$. The severe disorder of the peroxo, $\mathrm{NO}_{3}$ and uranyl groups in 2 provides no possibility to analyze its molecular geometry in detail, but the mutual disposition of the constituting moieties can still be assessed. Particularly, the equatorial planes of two $\mathrm{UO}_{8}$ polyhedra connected through the peroxo anion are not parallel (the corresponding dihedral angle is $c a .21^{\circ}$ ), and deviate from planarity. Although this deviation is a rare case, it was previously reported for several peroxo complexes of uranium. ${ }^{19}$

Compounds $\mathbf{3}$ and $\mathbf{4}$ are isostructural, although the number of solvate molecules in their structures obtained from X-ray diffraction is not equal, probably due to the loss of solvent molecules in air. These contain only half of the molecule in the asymmetric unit with Ln, N1 and O5 atoms situated on a two-fold rotation axis. The Ln atom in $\mathbf{3}$ and $\mathbf{4}$ coordinates three nitrate anions and two $\mathbf{L}$ ligands in a bidentate chelate mode to form a $\mathrm{LnO}_{10}$ coordination polyhedron (the molecular view of 3 is given in Fig. 4 as an example). The nitrate anions are situated in a T-shape according to the metal atom with the $\mathrm{NLnN}$ angles slightly deviating from $90^{\circ}$ (the angle value is

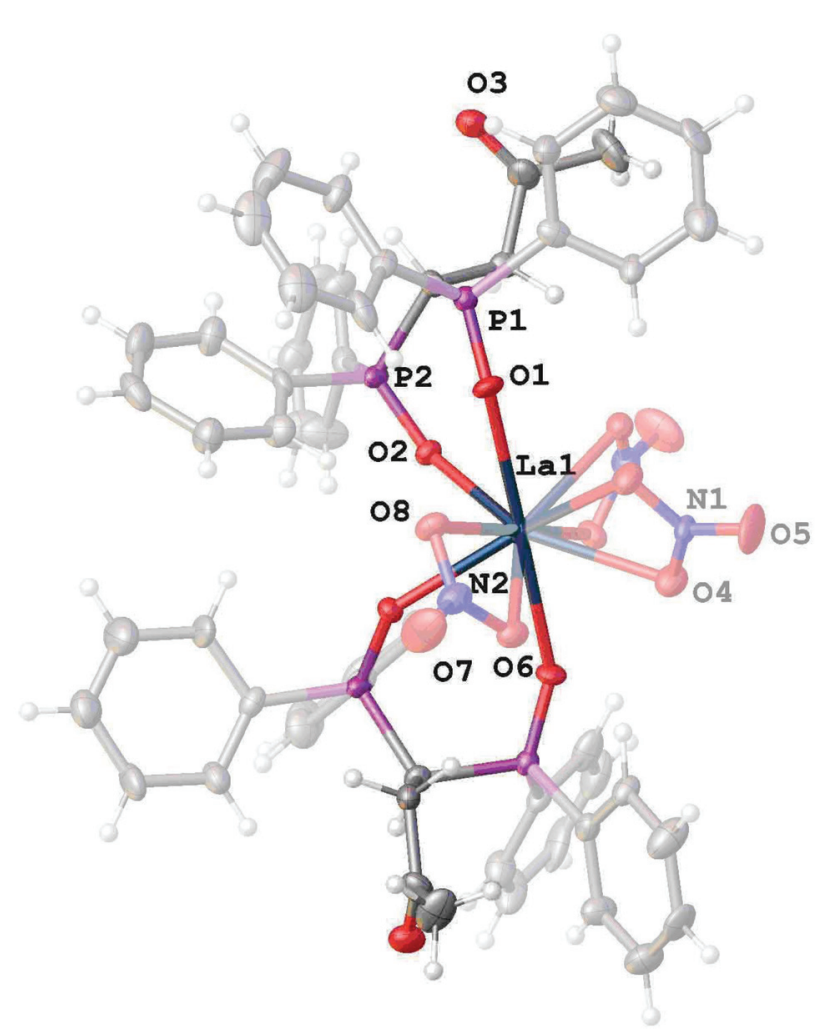

Fig. 4 General view of molecule 3 with the atoms represented as thermal ellipsoids drawn at $p=50 \%$. 
equal to $83.2(2)$ and $83.0(2)^{\circ}$ ) due to the electronic and steric effects of the $\mathbf{L}$ ligands.

The resulting polyhedron forms a pseudo-capped trigonal prism with the $\mathrm{N} 1$ atom in the capped position, if the nitrate anions are regarded as one polyhedron vertex (Fig. 5).

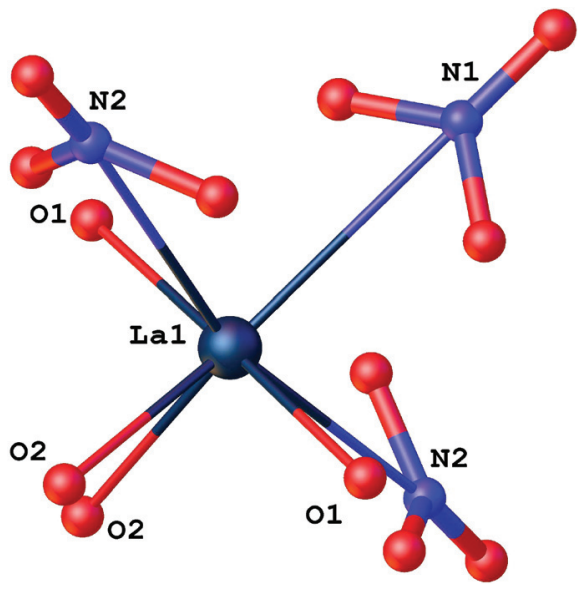

Fig. 5 Visualization of the pseudo-capped trigonal prismatic environment around $\mathrm{La}(\mathrm{III})$ in 3 .

In the closely related family of lanthanide nitrate complexes with $\mathbf{L}^{\prime}$, the compounds were characterized to be of the compositions $\left[\mathrm{Ln}\left(\mathrm{NO}_{3}\right)_{3}\left(\mathbf{L}^{\prime}\right)_{2}\right] \cdot \operatorname{solv}(\mathrm{Ln}=\mathrm{La}$, solv = EtOH; $\mathrm{Ln}=\mathrm{Ce}$, solv $=$ acetone), $\left[\mathrm{Ln}\left(\mathrm{NO}_{3}\right)_{2}\left(\mathrm{H}_{2} \mathrm{O}\right)\left(\mathbf{L}^{\prime}\right)_{2}\right]\left[\operatorname{Ln}\left(\mathrm{NO}_{3}\right)_{4} \mathbf{L}^{\prime}\right] \cdot \mathrm{MeCN}(\mathrm{Ln}=\mathrm{Pr}$, $\mathrm{Eu}),\left[\mathrm{Ln}\left(\mathrm{NO}_{3}\right)_{2}\left(\mathrm{H}_{2} \mathrm{O}\right)\left(\mathbf{L}^{\prime}\right)_{2}\right]\left(\mathrm{NO}_{3}\right) \cdot \operatorname{solv}\left(\mathrm{Ln}=\mathrm{Nd}\right.$, Gd, solv $=\mathrm{H}_{2} \mathrm{O}$; $\mathrm{Ln}=\mathrm{Ho}$, solv $=\mathrm{EtOH})$ and $\left[\mathrm{Ln}\left(\mathrm{NO}_{3}\right)\left(\mathbf{L}^{\prime}\right)_{3}\right]\left(\mathrm{NO}_{3}\right)_{2} \cdot \mathrm{solv}(\mathrm{Ln}=\mathrm{Gd}$, $\mathrm{Yb} ; \mathrm{Ln}=\mathrm{Gd}$, solv $=\mathrm{EtOH}) .{ }^{6}$ Thus, although a lanthanide cation can coordinate up to four bis(diphenylphosphino) methane dioxide ligands (as in the structure of $\left[\mathrm{Eu}\left(\mathbf{L}^{\prime}\right)_{4}\right]$ $\left.\left(\mathrm{ClO}_{4}\right)_{3} \cdot 2 \mathrm{H}_{2} \mathrm{O}\right),{ }^{20}$ nitrate anions compete with those for a place in the lanthanide coordination sphere. The ratio $\mathrm{Ln}: \mathrm{NO}_{3}: \mathbf{L}^{\prime}$ (or $\mathbf{L})=1: 3: 2$ is expected only for light elements (La, Ce); lanthanide contraction is accompanied by a decrease in this ratio as $1: 2: 2(\mathrm{Ln}=\mathrm{Pr}-\mathrm{Ho})$ or as $1: 1: 3(\mathrm{Ln}=\mathrm{Gd}-\mathrm{Yb})$. Thus, coordination isomerism is possible in this series.

Indeed, we succeeded to obtain complex 5 from ethanol for which the ratio is $\mathrm{Nd}: \mathrm{NO}_{3}: \mathbf{L}=1: 2: 2$ (Fig. 6).

It contains two $\mathbf{L}$ ligands in both the $\mathrm{P}(\mathrm{O}), \mathrm{P}(\mathrm{O})$-bidentate and tridentate coordination modes, and only two nitrate anions coordinated by the neodymium atom. The $\mathrm{NdO}_{9}$ polyhedron adopts a tricapped trigonal prismatic geometry (Fig. 7).

For compounds 3-5, the $\mathrm{Ln}-\mathrm{O}(\mathrm{L})$ bond distances are shorter than those for the Ln-O(nitrate) bonds (Table 2); and the latter bonds are typically alternated. In $\mathbf{5}$, the $\mathrm{Nd}-\mathrm{O}(\mathrm{C})$ bond is the longest, and, hence, the weakest among the coordination bonds. The lanthanide contraction for isostructural compounds $\mathbf{3}$ and $\mathbf{4}$ is expressed as a shortening of the respective coordination bonds.

The coordination of phosphoryl and acetyl groups does not affect the lengths of the $\mathrm{P}=\mathrm{O}$ and $\mathrm{C}=\mathrm{O}$ bonds, although the

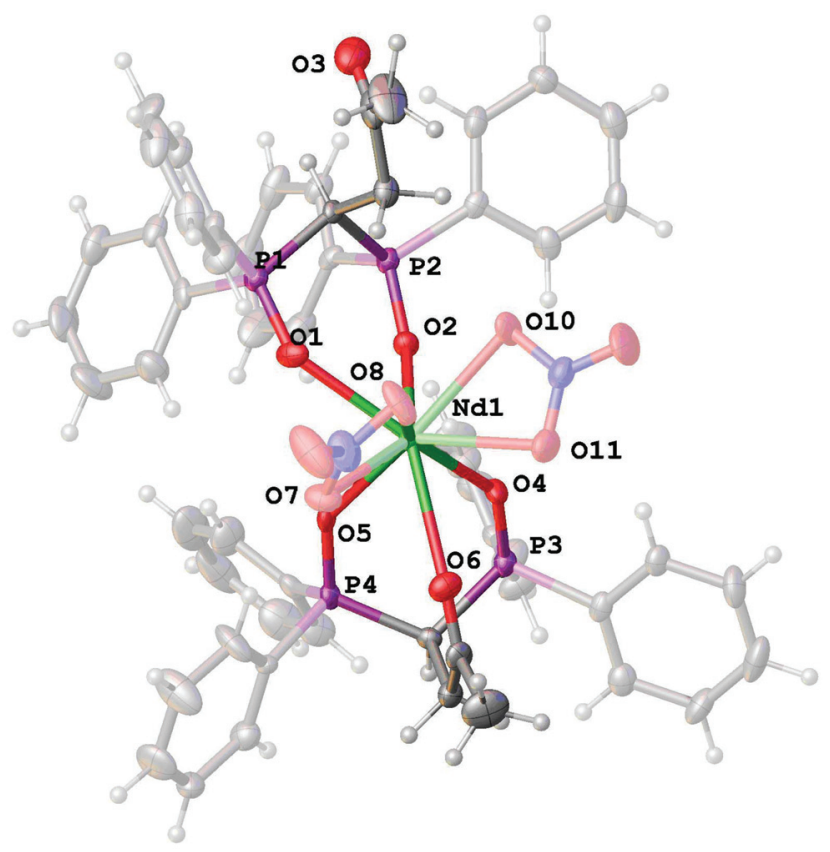

Fig. 6 General view of the complex cation $\left[\mathrm{Nd}\left(\mathrm{NO}_{3}\right)_{2} \mathrm{~L}_{2}\right]^{+}$in the structure of 5 with the atoms represented as thermal ellipsoids drawn at $p=50 \%$.

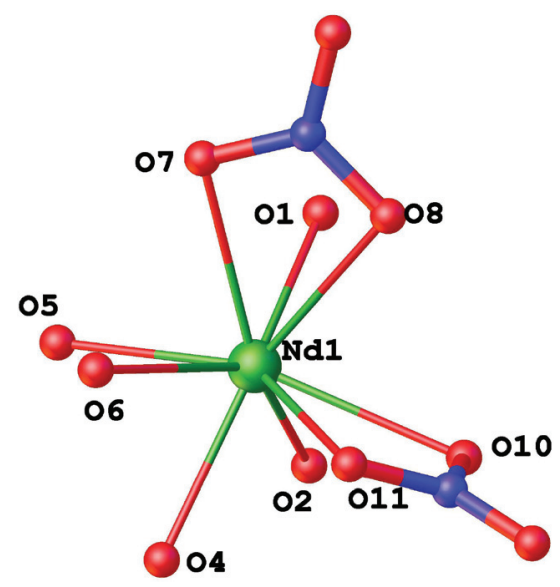

Fig. 7 Visualization of the tricapped trigonal prismatic environment around $\mathrm{Nd}(\mathrm{II})$ in 5 .

Table 2 Selected bond distances (Å) in complexes 3-5

\begin{tabular}{llll}
\hline Bond & $3(\mathrm{La})$ & $\mathbf{4}(\mathrm{Nd})$ & $\mathbf{5}(\mathrm{Nd})$ \\
\hline Ln-O1(L) & $2.541(6)$ & $2.5016(9)$ & $2.462(5)$ \\
Ln-O2(L) & $2.501(7)$ & $2.4573(9)$ & $2.410(4)$ \\
Ln-O4(L) & & & $2.389(4)$ \\
Ln-O5(L) & & & $2.405(5)$ \\
Ln-O(C) & & $1.214(2)$ & $2.656(5)$ \\
C=O (free) & $1.202(13)$ & & $1.217(9)$ \\
C=O (coordinated) & & & $1.222(7)$ \\
Ln-O (nitrate) & $2.599(8)-2.653(6)$ & $2.555(1)-2.609(1)$ & $2.536(5)-2.551(4)$ \\
P1-O1 & $1.491(7)$ & $1.4957(9)$ & $1.514(5)$ \\
P2-O2 & $1.504(7)$ & $1.5010(9)$ & $1.492(4)$ \\
P3-O4 & & & $1.496(4)$ \\
P4-O5 & & & $1.505(4)$
\end{tabular}


oxygen atom of the longest $\mathrm{P}=\mathrm{O}$ bond in $\mathbf{5}$ is involved in $\mathrm{O}-$ $\mathrm{H} \cdots \mathrm{O}$ hydrogen bonding with ethanol molecules $(r(\mathrm{O} \cdots \mathrm{O})=$ $\left.3.844(8) \AA, \angle(\mathrm{OHO})=165.9^{\circ}\right)$ (Fig. S4, ESI $\dagger$ ). With the exception of one ligand in $\mathbf{5}$, the acetyl group of $\mathbf{L}$ in complexes $\mathbf{1 - 5}$ is involved in the $\mathrm{CH} \cdots \mathrm{O}=\mathrm{C}$ intra- and intermolecular bonding (Fig. S1-S4, ESI $\dagger$ ). The most significant noncovalent $\mathrm{CH} \cdots \mathrm{O}=\mathrm{C}$ interactions are observed in complexes 3 and 4 with the shortest $\mathrm{O} \cdots \mathrm{H}$ distances $2.53-2.55 \AA$ and corresponding value of the $\mathrm{CHO}$ angle $\sim 145^{\circ}$ (Fig. S3, ESI $\dagger$ ). In our opinion, the presence of an uncoordinated acetyl group available for complex...solvate hydrogen bonding could be the reason for the enhanced extraction ability of $\mathbf{L}$ compared with $\mathbf{L}^{\prime}$. To reveal the crystal packing effects on the IR spectra of 1 and 3-5 in the solid state, we analyzed the closest environment of these complexes. The $\mathrm{O}-\mathrm{H} \cdots \mathrm{O}$ bond in $\mathbf{5}$ should affect the $\mathrm{P}=\mathrm{O}$ vibrations. Moreover, one can expect the effect of weak intermolecular $\mathrm{C}-\mathrm{H} \cdots \mathrm{O}=\mathrm{C}$ interactions (for $\mathbf{3}$ and 4 ) on acetyl group vibration.

Along with numerous $\mathrm{C}-\mathrm{H} \cdot \mathrm{\cdots O}$ intramolecular bonds, intramolecular $\pi$-bonding can be suggested for 1-5 that could affect the stability of complexes. These are analyzed in the next section.

2.2.2. AIM analysis for complexes 1-5. It is well known that the topological analysis of electron density (ED) $\rho(\mathbf{r})$ according to Bader's "Atom in Molecules" theory (AIM) ${ }^{21}$ derived from $a b$ initio calculations in conjunction with Espinosa's correlation $\left(E_{\text {cont }}=-1 / 2 V(\mathbf{r})\right)^{22}$ makes it possible to estimate the interaction energy $\left(E_{\text {cont }}\right)$ with sufficient accuracy. ${ }^{23}$

To evaluate the $\pi$-stacking energy, topological analysis of the ED for complexes 1-5 was performed using X-ray geometry data at the DFT level of theory. Unlike the neutral compounds 1-4, complex 5 is both ionic and paramagnetic, for which convergence of SCF equations has not been achieved in spite of our efforts to change the basis set for the neodymium atom or convergence algorithms. We calculated this value for model free ligands in geometrical configuration as in the X-ray structure of complex 5 .
The AIM results are presented in Fig. 8 and in Table 3. Molecular graphs of complexes 1-5 exhibit various sets of bond critical points (BCP) and bond paths corresponding to different types of $\pi$-stacking interactions.

The change in the parameters of the intramolecular $\pi$-stacking interactions (Table 3) for complexes 1-5 depends on the mutual geometric configuration of the benzene rings (Table 4). The larger the distance between the rings and corresponding interplanar angle the smaller the interaction energy value. The topology of molecular graphs is affected by the parallel shift of two benzene rings (e.g. for complexes 2 and 3), hence, the number of bond paths and overall interaction energy decrease. The most pronounced stacking interaction is observed in complex 1 (interplane distances are $3.505 \AA$ ). The total energy of the $\pi$-stackings in 1-5 amounts to $2.3,4.0,2.8,3.2$ and

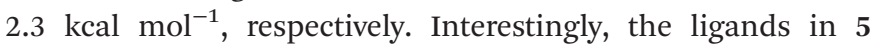
exhibit different coordinations: bi- and tridentate fashion. This leads to different molecular graphs in the $\pi$-stacking interaction fragment ( $\mathbf{5} \mathbf{a}$ and $\mathbf{5 b}$ in Fig. 8), containing one and two bond paths for tridentate and bidentate ligands, respectively. Thus, the $\pi$-stacking interaction in the tridentate ligand (5a) is the weakest (only $0.8 \mathrm{kcal} \mathrm{mol}^{-1}$ ) in the series studied.

The obtained $\pi$-stacking interaction energy values are close to those for intramolecular $\pi$-stacking in a Co(III) complex $^{24}$ of about 1-3 kcal mol${ }^{-1}$ and to those for intramolecular interligand $\pi$-stacking interactions in Lu(III) complexes $^{25}$ of about 1.9-3.3 kcal mol ${ }^{-1}$.

The analysis of literature data on the structure of crystalline complexes of methylenediphosphine dioxide $\mathbf{L}^{\prime}$ with uranyl nitrate $\left[\mathrm{UO}_{2}\left(\mathrm{NO}_{3}\right)_{2} \mathbf{L}^{\prime}\right](7)^{7}$ and lanthanum nitrate $\left[\mathrm{La}\left(\mathrm{NO}_{3}\right)_{3}\left(\mathbf{L}^{\prime}\right)_{2}\right] \cdot$ EtOH $(\mathbf{8})^{6}$ also indicates $\pi$-stacking in the molecules of coordinated ligand $\mathbf{L}^{\prime}$. However, the stacking interactions in the complexes of unmodified ligand $\mathbf{L}^{\prime}$ are weaker than in complexes of $\mathbf{L}$ of the same chelate coordination. Thus, the dihedral angles between contacting planes in uranyl complexes 1 and 7 are $9.25^{\circ}$ and $13.17^{\circ}$, respectively, while the

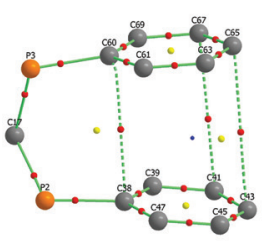

1

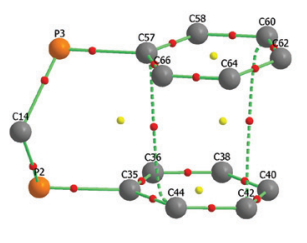

2

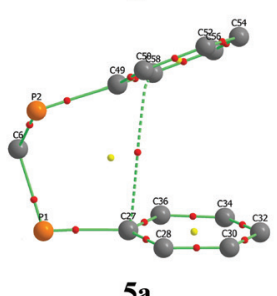

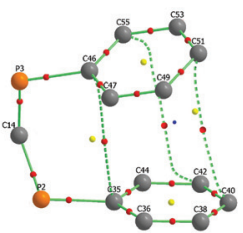

3

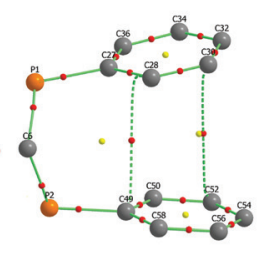

$\mathbf{5 b}$

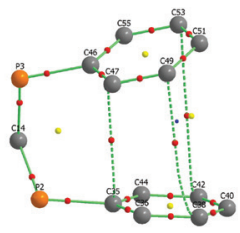

4

Fig. 8 The fragments of QTAIM graphs for complexes 1-5 exhibiting $\pi$-stacking interactions in these complexes (a, $\mathbf{b}-$ tri- and bidentate ligand coordination in complex 5). Hydrogen atoms are omitted for clarity. Color codes for the atoms: orange (P), grey (C). The $\pi$-stacking bond paths are shown as green dotted lines; BCPs $(3 ;-1)$ are red, ring $(3 ;+1)$ critical points are yellow, and cage $(3 ;+3)$ critical points are blue. 
Table 3 Topological parameters (QTAIM) in the critical points $(3,-1)$ for $\pi$-stacking interactions in complexes $1-4$ and complex cation 5 at the $\mathrm{PBE} 0 / 6-311+\mathrm{G}^{* *}$ level

\begin{tabular}{|c|c|c|c|c|c|c|}
\hline Complex & $\mathrm{BCP}(3 ;-1)$ & $\rho(\mathbf{r})$, a.u. & $\nabla^{2} \rho(\mathbf{r})$, a.u. & $V(\mathbf{r})$, a.u. & $E_{\text {cont }}, \mathrm{kcal} / \mathrm{mol}$ & $\sum E_{\text {cont }}, \mathrm{kcal} / \mathrm{mol}$ \\
\hline \multirow[t]{2}{*}{1} & C38-C60 & +0.008252 & +0.022976 & -0.003955 & 1.3 & \multirow[t]{2}{*}{2.3} \\
\hline & C45-C63 & +0.003848 & +0.010428 & -0.001669 & 0.5 & \\
\hline \multirow[t]{2}{*}{2} & C44-C57 & +0.008598 & +0.024180 & -0.003988 & 1.3 & \multirow[t]{2}{*}{2.0} \\
\hline & C42-C60 & +0.005467 & +0.014297 & -0.002330 & 0.7 & \\
\hline \multirow[t]{2}{*}{3} & C35-C46 & +0.006458 & +0.018423 & -0.002927 & 0.9 & \multirow[t]{2}{*}{1.4} \\
\hline & C40-C51 & +0.001889 & +0.005211 & -0.000794 & 0.3 & \\
\hline & C39-C49 & +0.003703 & +0.009296 & -0.001505 & 0.5 & \multirow{2}{*}{1.6} \\
\hline & C42-C52 & +0.001324 & +0.003886 & -0.000592 & 0.2 & \\
\hline \multirow[t]{3}{*}{5} & $\mathrm{C} 27-\mathrm{C} 58^{a}$ & $+0.005527^{a}$ & $+0.015985^{a}$ & $-0.002511^{a}$ & $0.8^{a}$ & \multirow{3}{*}{$\begin{array}{l}0.8^{a} \\
1.5^{b}\end{array}$} \\
\hline & $\mathrm{C} 28-\mathrm{C} 49^{b}$ & +0.007119 & +0.019434 & -0.003138 & $1.0^{b}$ & \\
\hline & $\mathrm{C} 30-\mathrm{C} 52^{b}$ & +0.003728 & +0.009775 & -0.001713 & $0.5^{b}$ & \\
\hline
\end{tabular}

${ }^{a}$ For tridentate ligand coordination. ${ }^{b}$ For bidentate ligand coordination.

Table 4 Geometrical parameters of $\pi$-stacking ${ }^{a}$ for complexes 1-4 and complex cation 5

\begin{tabular}{lllllll}
\hline & $\mathbf{1}$ & $\mathbf{2}$ & $\mathbf{3}$ & $\mathbf{4}$ & $\mathbf{5}^{b}$ & $\mathbf{5}^{c}$ \\
\hline $\mathrm{M}$ & $\mathrm{U}$ & $\mathrm{U}$ & $\mathrm{La}$ & $\mathrm{Nd}$ & $\mathrm{Nd}$ & $\mathrm{Nd}$ \\
$d, \AA$ & 3.505 & 3.710 & 3.816 & 3.849 & 4.644 & 3.831 \\
$l, \AA$ & 3.505 & 3.760 & 3.827 & 3.841 & 4.123 & 3.825 \\
$\beta, \circ$ & 9.25 & 8.03 & 23.15 & 24.21 & 29.82 & 13.76
\end{tabular}

${ }^{a} d$ is the average distance between the contacting planes; $l$ is the centroid-centroid distance; $\beta$ is the average dihedral angle between the planes of contacting fragments. ${ }^{b}$ For tridentate ligand coordination. ${ }^{c}$ For bidentate ligand coordination.

distances between centroids are 3.505 and $3.736 \AA$, respectively. In the lanthanum nitrate complexes with $\mathbf{L}$ and $\mathbf{L}^{\prime}, \mathbf{3}$ and 8, the noted angles are 23.1 and $12.17,12.66^{\circ}$, while the distances are 3.816 and $3.940,4.079 \AA$ (the contacting fragments in complex $\mathbf{8}$ are skewed toward each other).

Thus, the $\pi$-stacking interaction between the two Ph substituents at the phosphorus atom is observed in molecule(s) of coordinated ligand $\mathbf{L}$ for all of the crystalline complexes $\mathbf{1 - 5}$. The highest energy of the $\pi$-stacking interaction was found for bisligand uranyl complex 2 . The change of ligand denticity from $\mathrm{P}(\mathrm{O}), \mathrm{P}(\mathrm{O})$-bidentate to $\mathrm{P}(\mathrm{O}), \mathrm{P}(\mathrm{O}), \mathrm{C}(\mathrm{O})$-tridentate almost doubly decreases the energy of the $\pi$-stacking interaction (see Table 3).

The above discourse deals with the stabilization of complexes in a crystal, but the situation may change in solution. Solvent nature is known to considerably affect the aromatic $\pi$-stacking interaction. However, $\pi$-stacking interactions are retained as a rule in dipolar aprotic solvents. ${ }^{26}$

2.2.3. IR spectroscopy characterization. The X-ray structures were compared with the IR spectra of the same complexes (Table 5). The formation of the $\mathrm{P}=\mathrm{O} \rightarrow \mathrm{M}$ coordination bond results in the shift of the $\nu(\mathrm{P}=\mathrm{O})$ band in the IR spectra of crystalline complexes 1 and 3-6 by $\sim 40 \mathrm{~cm}^{-1}$ to the low frequency region with respect to the band of the free ligand (Table 5), which is slightly lower than in similar complexes of phosphoryl-containing ligands $\left(\Delta \nu(\mathrm{P}=\mathrm{O}) \sim 65 \mathrm{~cm}^{-1}\right.$ for $\mathrm{UO}_{2}$ complexes, ${ }^{7,27}$ and $\sim 50 \mathrm{~cm}^{-1}$ for Ln complexes $\left.{ }^{28}\right)$. The spectrum of complex 5 , along with the $\nu(\mathrm{P}=\mathrm{O})$ band at $1160 \mathrm{~cm}^{-1}$, also displays a band at $1150 \mathrm{~cm}^{-1}$ responsible for vibrations of the coordinated $\mathrm{P}=\mathrm{O}$ group participating in the formation of a supplementary weak $\mathrm{H}$ bond with a solvate $\mathrm{EtOH}$ molecule. The formation of the $\mathrm{C}=\mathrm{O} \rightarrow \mathrm{M}$ coordination bond in complex 5 causes a shift of the $\nu(\mathrm{C}=\mathrm{O})$ band to the lowfrequency region but only by $9 \mathrm{~cm}^{-1}$ relative to the band of the free ligand, whereas usually coordination of $\mathrm{C}=\mathrm{O}$ to a cation leads to a shift of $20-25 \mathrm{~cm}^{-1}$ for lanthanide complexes and $20-60 \mathrm{~cm}^{-1}$ for $\mathrm{UO}_{2}$ complexes. ${ }^{16,27 \mathrm{~b}, 29}$ The band of the uncoordinated $\mathrm{C}=\mathrm{O}$ group in the spectrum of crystalline complex 1 is observed ${ }^{30}$ at the same frequency as in the spectrum of the free ligand (Table 5). In the isostructural complexes of La and Nd ( 3 and 4 , respectively), the shift of the $\nu(\mathrm{C}=\mathrm{O})$ band by $4-3 \mathrm{~cm}^{-1}$ corresponds to vibrations of the $\mathrm{C}=\mathrm{O}$ group involved in weak intra- and intermolecular $\mathrm{CH} \cdots \mathrm{O}=\mathrm{C}$ interactions (Table 5). The spectrum of crystalline complex 5 exhibits a band of the free $\mathrm{C}=\mathrm{O}$ group, that does not become involved in supplementary interactions, at $1722 \mathrm{~cm}^{-1}$.

The IR spectra of complexes $\mathbf{1}$ and 3-6 show absorption bands of bidentate nitrate ions at $\sim 1500 \mathrm{~cm}^{-1}$ for $\nu(\mathrm{N}=\mathrm{O})$, and $\sim 1300 \mathrm{~cm}^{-1}$ for $\nu_{\text {as }}\left(\mathrm{NO}_{2}\right)$ (Table 5). Full details of the nitrate bands are shown in Table S1 (ESI $\dagger$ ). In contrast to other complexes, X-ray structure 5 includes, along with bidentate coordinated nitrate ions, outer-sphere "free" nitrate ions involved in many weak $\mathrm{CH} \cdots \mathrm{ON}$ interactions. The symmetry of an uncoordinated nitrate ion is known to be violated on weak interactions in crystal or contact ion pairs (CIPs) on account of cation-anion interactions that cause strong splitting of the $\nu_{\mathrm{E}}\left(\mathrm{NO}_{3}\right)$ vibration. ${ }^{31}$ As should be expected, the spectrum of crystalline compound 5 shows no absorption for the free nitrate ion, which usually appears as a narrow intense band at $\sim 1370 \mathrm{~cm}^{-1},{ }^{31}$ but displays a wide absorption in the region $1300-1500 \mathrm{~cm}^{-1}$ with several submaxima at 1338,1384 , and $1396 \mathrm{~cm}^{-1}$. 
Table 5 Selected IR $\left(\nu, \mathrm{cm}^{-1}\right)$ and ${ }^{31} \mathrm{P}\left\{{ }^{1} \mathrm{H}\right\}$ NMR spectroscopic data for the ligand $\mathrm{L}$ and its complexes 1 and $3-6$ in the solid state and in solution (0.01 M)

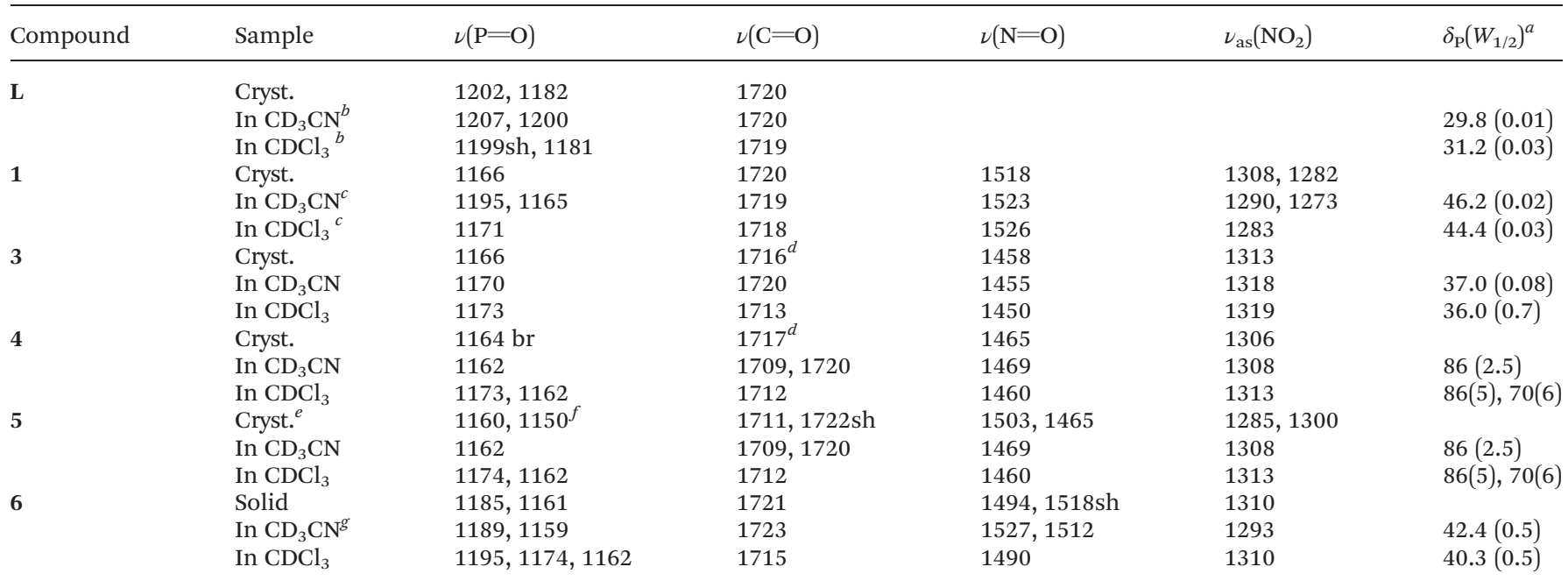

${ }^{a}$ The band width at half-height (in ppm). ${ }^{b} c=0.02 \mathrm{M}$. ${ }^{c}$ Saturated solution, $c \sim 0.003 \mathrm{M}$. ${ }^{d}$ Non-covalent $\mathrm{CH} \cdots \mathrm{O}=\mathrm{C}$ interaction (see section 2.2 .1 ). ${ }^{e} \mathrm{~A}$ wide absorption in the region $1300-1400 \mathrm{~cm}^{-1}$ (weak $\mathrm{CH} \cdots \mathrm{ON}$ interaction of "free" nitrate - see section 2.2 .3 ). ${ }^{f}$ Weak $\mathrm{OH} \cdots \mathrm{O}$ bonding between coordinated $\mathrm{P}=\mathrm{O}$ and $\mathrm{EtOH}$ (see section 2.2.1). ${ }^{g}$ The strong band at $1356 \mathrm{~cm}^{-1}-\nu_{\mathrm{E}}\left(\mathrm{NO}_{3}\right)$ (see section 2.3.1).

According to elemental analysis and X-ray crystallographic data, complexes 3 and $\mathbf{4}$ contain solvate acetonitrile, but the IR spectra of 3 and 4 exhibit no absorption for the CN group. ${ }^{32}$ The IR spectra of $\mathbf{5}$ show bands typical for outer-sphere ethanol molecules in the region of $\sim 3400 \mathrm{~cm}^{-1}$.

We failed to prepare complex 6 in a crystalline state. But, elemental analysis and IR spectra allow us to suppose unambiguously that one ligand molecule in bisligand complex 6 is coordinated in a $\mathrm{P}(\mathrm{O}), \mathrm{P}(\mathrm{O})$-bidentate mode, while another molecule has a $\mathrm{P}(\mathrm{O})$-monodentate coordination. The IR spectrum of solid complex 6 (Table 5) shows bands of free $\mathrm{P}=\mathrm{O}$ and $\mathrm{C}=\mathrm{O}$ groups at 1185 and $1721 \mathrm{~cm}^{-1}$ along with the band of the coordinated $\mathrm{P}=\mathrm{O}$ group at $1161 \mathrm{~cm}^{-1}$. The strong broad IR bands of bidentate $\mathrm{NO}_{3}$ groups are detected at 1494,1310 and $1030 \mathrm{~cm}^{-1}$. In the region of $3200-3400 \mathrm{~cm}^{-1}$ the band of metal-coordinated water (typically at $\sim 3200 \mathrm{~cm}^{-1}$ ) is absent. In accordance with these data, one can suppose that compound 6 most likely has the structure of neutral mononuclear complex $[\mathrm{Lu}\{\mathrm{P}(\mathrm{O}), \mathrm{P}(\mathrm{O})-\mathbf{L}\}-$ $\left.\{\mathrm{P}(\mathrm{O})-\mathbf{L}\}\left(\mathrm{O}, \mathrm{O}-\mathrm{NO}_{3}\right)_{3}\right]$, and that the coordination number of lutetium is nine.
Thus, lanthanide contraction is observed for the structure of the studied neutral complexes of ligand $\mathbf{L}$. The coordination number (CN) of light lanthanides (La and $\mathrm{Nd}$ ) in complexes 3 and 4, $\left[\mathrm{Ln}\{\mathrm{P}(\mathrm{O}), \mathrm{P}(\mathrm{O})-\mathrm{L}\}_{2}\left(\mathrm{NO}_{3}\right)_{3}\right]$, equals ten, while the $\mathrm{CN}$ of lutetium in complex 6, $\left[\mathrm{Lu}\{\mathrm{P}(\mathrm{O}), \mathrm{P}(\mathrm{O})-\mathbf{L}\}\{\mathrm{P}(\mathrm{O})-\mathbf{L}\}\left(\mathrm{O}, \mathrm{O}-\mathrm{NO}_{3}\right)_{3}\right]$, is nine.

\subsection{Solution state characterization}

The structure of the complexes in acetonitrile (AN) and chloroform solutions was studied by IR and multinuclear NMR spectroscopy. We were interested to study the effect of solvent nature on the structure of complexes and ligand $\mathbf{L}$ coordination mode. The parameters of IR and ${ }^{31} \mathrm{P},{ }^{1} \mathrm{H}$, and ${ }^{13} \mathrm{C} \mathrm{NMR}$ spectra for the complexes 1, 3-6 in comparison with the data for the free ligand $\mathbf{L}$ are given in Tables 5-7 (see also Fig. S5$\mathrm{S} 12, \mathrm{ESI} \dagger)$.

The coordination of the $\mathrm{P}=\mathrm{O}$ groups can be reliably determined from the NMR spectra of compounds $\mathbf{1}$ and 3-6. The signals of the phosphorus nuclei as well as the protons and carbon nuclei of neighboring groups exhibit expected shifts (Tables 5-7) close to those for known complexes of akin phos-

Table 6 Selected ${ }^{1} \mathrm{H}$ and ${ }^{13} \mathrm{C}$ NMR data for the ligand $\mathrm{L}$ and its complexes $1,3-6^{a}$ in $\mathrm{CD}_{3} \mathrm{CN}(0.01 \mathrm{M})$ at $25^{\circ} \mathrm{C}$

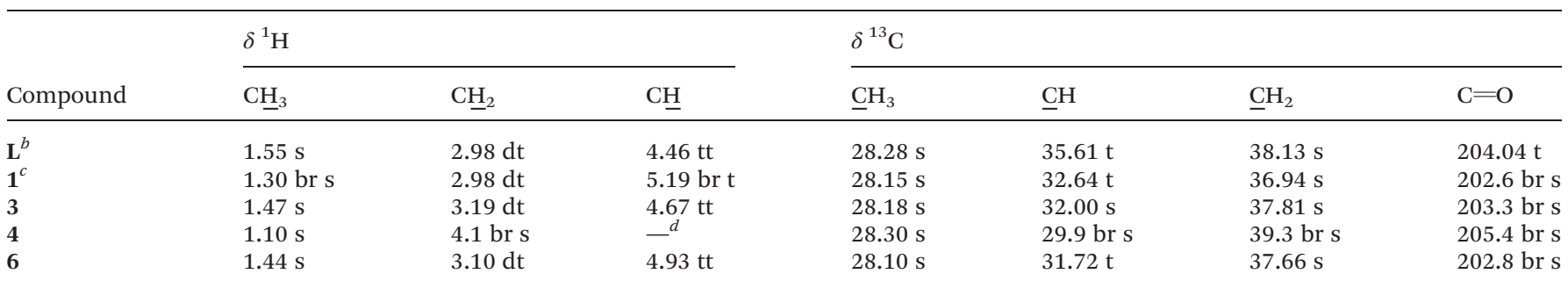

${ }^{a}$ Spectra of complexes 4 and 5 are identical. ${ }^{b} 0.02 \mathrm{M}$ solution. ${ }^{c}$ Saturated solution, $c \sim 0.003 \mathrm{M} .{ }^{d}$ Not observed. 
Table 7 Selected ${ }^{1} \mathrm{H}$ and ${ }^{13} \mathrm{C}$ NMR data for the ligand $\mathrm{L}$ and its complexes 1, 3, and 6 in $\mathrm{CDCl}_{3}(0.01 \mathrm{M})$ at $25^{\circ} \mathrm{C}$

\begin{tabular}{|c|c|c|c|c|c|c|c|}
\hline Compound & \multicolumn{3}{|l|}{$\delta{ }^{1} \mathrm{H}$} & \multicolumn{4}{|l|}{$\delta^{13} \mathrm{C}$} \\
\hline $\mathbf{1}^{b}$ & $1.38 \mathrm{~s}$ & $2.84 \mathrm{dt}$ & $4.95 \mathrm{br} \mathrm{t}$ & $28.83 \mathrm{~s}$ & 31.93 br s & $37.72 \mathrm{~s}$ & 203.4 br s \\
\hline 3 & $1.62 \mathrm{~s}$ & $3.36 \mathrm{t}$ & 4.63 br s & $29.17 \mathrm{~s}$ & 32.43 br s & 39.15 br s & 206.2 br s \\
\hline 6 & $1.61 \mathrm{~s}$ & $3.28 \mathrm{t}$ & $5.04 \mathrm{br} \mathrm{s}$ & $28.98 \mathrm{~s}$ & $33.05 \mathrm{t}$ & $39.81 \mathrm{~s}$ & 205.7 br s \\
\hline
\end{tabular}

phoryl-containing ligands. ${ }^{8 a, c, 27 a, b, 28}$ The coordination of phosphoryl-containing ligands with $\mathrm{UO}_{2}(\mathrm{II}), \mathrm{La}(\mathrm{III}), \mathrm{Lu}(\mathrm{III})$, and $\mathrm{Nd}(\mathrm{III})$ cations causes a downfield shift in the signals of the phosphorus nuclei by $5-60 \mathrm{ppm}$, while signals of the carbon nuclei of neighboring groups are shifted upfield; the signals of the paramagnetic neodymium complex show considerable broadening. The participation of the $\mathrm{C}=\mathrm{O}$ group in coordination appears in the ${ }^{13} \mathrm{C}$ and ${ }^{1} \mathrm{H}$ NMR spectra as a downfield shift of the carbon signals of the $\mathrm{C}=\mathrm{O}$ group as well as the carbon and proton nuclei signals of neighboring $\mathrm{CH}_{3}$ and $\mathrm{CH}_{2}$ groups relative to the free ligand signals (Tables 6 and 7), however, the value of these shifts in the spectra of complexes of ligand $\mathbf{L}$ is lesser than those of corresponding complexes for the majority of carbonyl ligands (for example $16,27 \mathrm{~b}, 29 \mathrm{~b}$ ).

2.3.1. Acetonitrile solutions. Uranyl complex 1 is poorly soluble in AN. The IR spectrum of its saturated solution shows the band of the coordinated $\mathrm{P}=\mathrm{O}$ group at $1165 \mathrm{~cm}^{-1}$ as well as the bands of free $\mathrm{P}=\mathrm{O}$ and $\mathrm{C}=\mathrm{O}$ groups at 1195 and $1719 \mathrm{~cm}^{-1}$. The bands of the nitrato groups are virtually retained when compared with the spectrum of the crystalline sample (Table 5). One can suppose that the ligand adopts a $\mathrm{P}(\mathrm{O})$-monodentate coordination in AN solution, and the coordination sphere of the cation is supplemented by solvent molecules, while the neutral complex has the structure $\left[\mathrm{UO}_{2}\{\mathrm{P}(\mathrm{O})-\mathrm{L}\}\left(\mathrm{OO}-\mathrm{NO}_{3}\right)_{2} \cdot \mathrm{MeCN}\right]$.

The NMR spectra of compound 1 (Tables 5 and 6) agree well with the proposed structure. Certain signals in the spectra are broadened. The ${ }^{31} \mathrm{P}$ NMR spectrum displays only one slightly broadened signal, which seems to be explained by fast exchange processes. The signal is shifted downfield relative to the signal of the free ligand by $16.4 \mathrm{ppm}$. In the ${ }^{13} \mathrm{C}$ NMR spectrum, the carbon signals of the $\mathrm{C}=\mathrm{O}, \mathrm{CH}_{3}$, and $\underline{\mathrm{CH}}_{2}$ groups are upfield shifted (Table 6). The largest upfield shift $(-2.97 \mathrm{ppm})$ is observed for the broadened signal of the $\underline{\mathrm{CH}}$ group, which is typical when the $\mathrm{P}=\mathrm{O}$ group is involved in the coordination. The corresponding effects are observed in the ${ }^{1} \mathrm{H}$ NMR spectrum (Table 6).

The lanthanide complexes have good solubility in AN, chloroform, and methanol. According to the IR spectral data, the structure of the crystalline lanthanum complex 3 is retained in AN solution (Scheme 4). The bands of the $\mathrm{P}=\mathrm{O}$, $\mathrm{C}=\mathrm{O}$ groups and nitrate ions have expected frequencies (Table 5), the complicated pattern in the spectrum of the crystalline sample caused by supplementary weak interactions

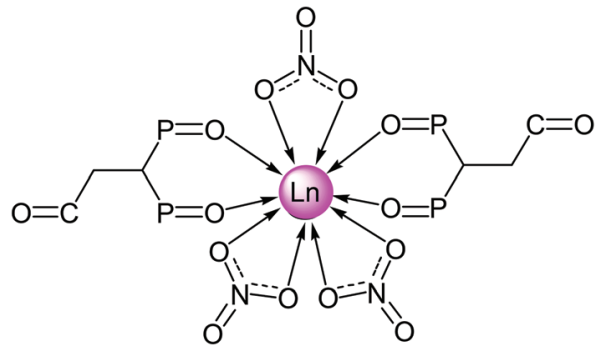

Scheme 4 Complex $3(\mathrm{Ln}=\mathrm{La})$ in the crystalline state and in AN solution, and complex $4(\mathrm{Ln}=\mathrm{Nd})$ in the crystalline state.

disappears. Bisligand complex 3 in AN solution, like in the crystalline state, seems to remain neutral $\left[\mathrm{La}\{\mathrm{P}(\mathrm{O}), \mathrm{P}(\mathrm{O})-\mathrm{L}\}_{2^{-}}\right.$ $\left.\left(\mathrm{OO}-\mathrm{NO}_{3}\right)_{3}\right]$, where the $\mathrm{CN}$ of lanthanum is ten.

NMR spectral data for compound 3 (Tables 5 and 6) agree well with the proposed structure (Scheme 4). ${ }^{31} \mathrm{P}$ NMR spectra display a sole narrow signal $\left(W_{1 / 2}=0.08 \mathrm{ppm}\right)$ of the phosphorus nuclei downfield shifted by $7.2 \mathrm{ppm}$ from its position in the free ligand. The signals of indicator groups $\left(\mathrm{C}=\mathrm{O}, \mathrm{CH}_{3}\right.$, and $\mathrm{CH}_{2}$ ) in the ${ }^{13} \mathrm{C}$ NMR are shifted upfield, which indicate the lack of coordination of the $\mathrm{C}=\mathrm{O}$ group. The largest shift in the ${ }^{13} \mathrm{C}$ NMR spectrum is observed for the signals of the $\mathrm{CH}$ groups $(-3.61 \mathrm{ppm})$. The shifts in the ${ }^{1} \mathrm{H}$ NMR spectrum are less considerable (Table 6), the protons of the $\mathrm{CH}_{3}$ group show the least shift $(-0.08 \mathrm{ppm})$, while the protons of $\mathrm{CH}$ and $\mathrm{CH}_{2}$ groups exhibit the largest shift $(0.21 \mathrm{ppm})$. A fine signal structure is observed in the spectrum.

IR and NMR spectra of neodymium complexes $\mathbf{4}$ and $\mathbf{5}$ in AN solution are identical (Tables 5 and 6). The complications in the IR spectrum of the crystalline sample of $\mathbf{5}$ are caused by weak interactions in the crystal that disappear in the solution spectrum. The main analytical bands have close positions to those in the spectrum of crystalline 5 (Table 5). We observed no band for the vibrations of free nitrate ions, expected at $\sim 1360 \mathrm{~cm}^{-1}$. Both complexes seem to be present in AN solution as a contact ion pair $[\mathrm{Nd}\{\mathrm{P}(\mathrm{O}), \mathrm{P}(\mathrm{O})-\mathrm{L}\}\{\mathrm{P}(\mathrm{O}), \mathrm{P}(\mathrm{O}), \mathrm{C}(\mathrm{O})-\mathrm{L}\}$ $\left.\left(\mathrm{OO}-\mathrm{NO}_{3}\right)_{2}\right]^{+} \cdot\left(\mathrm{NO}_{3}\right)^{-}$, where the $\mathrm{CN}$ of neodymium is nine (Scheme 5).

The sole signal in the ${ }^{31} \mathrm{P}$ NMR spectrum of neodymium complex 4 in AN at 86 ppm (analysis of NMR spectra is given for one complex because the spectra of solutions of $\mathbf{4}$ and 5 are identical) is considerably broadened $\left(W_{1 / 2}=2.5 \mathrm{ppm}\right)$. In 


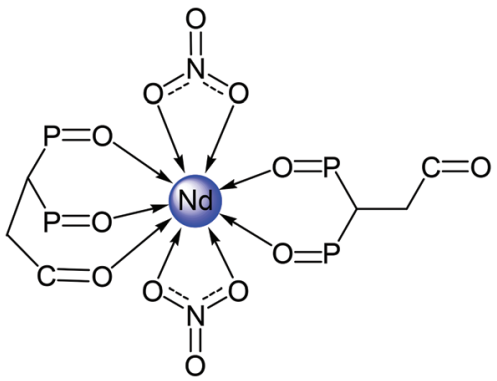

Scheme 5 Complex cation of compounds 4 and 5 in AN solution.

the ${ }^{1} \mathrm{H}$ NMR spectrum, the proton signals of all groups except for $\mathrm{CH}_{3}$ and $\mathrm{CH}_{2}$ are also broadened, no signal for the $\mathrm{CH}$ protons is observed probably due to both paramagnetic properties of the neodymium cation and dynamic equilibria in solution. The signals of the $\mathrm{CH}_{3}$ and $\mathrm{CH}_{2}$ groups are shifted from their positions in the free ligand by -0.14 and $1.12 \mathrm{ppm}$, respectively. The ${ }^{13} \mathrm{C}$ NMR spectrum exhibits one set of signals, which seem to correspond to the fast dynamic equilibrium of several complex species. Alterations of the chemical shifts in the ${ }^{13} \mathrm{C}$ NMR spectrum agree well with the suggested complex structure (Scheme 5).

According to IR spectroscopic measurements, the structures of the lutetium complex 6 in AN solution and in the solid state differ. The main difference is the emergence of a strong vibrational band of the free nitrate ion at $1356 \mathrm{~cm}^{-1}$. Furthermore, strong bands of bidentate coordinated nitrato groups are detected at 1527,1512 , and $1293 \mathrm{~cm}^{-1}$. Vibration bands of the $\mathrm{P}=\mathrm{O}$ and $\mathrm{C}=\mathrm{O}$ groups are observed at almost the same frequencies as in the spectrum of the solid sample (Table 5). Obviously, ligand molecules retain the same coordination as in the solid complex. In accordance with these data, one can suppose that complex 6 in AN solution exists as either a solvent-separated ion pair (SSIP) or cationic complex $[\mathrm{Lu}\{\mathrm{P}(\mathrm{O})$, $\left.\mathrm{P}(\mathrm{O})-\mathbf{L}\} \mathrm{P}(\mathrm{O})-\mathbf{L}\}\left(\mathrm{OO}-\mathrm{NO}_{3}\right)_{2}\right]^{+}$and free nitrate ion. In this case, the $\mathrm{CN}$ of lutetium should be equal to seven. Both the forms, most probably, are in equilibrium. Since CNs of lutetium of eight and nine ${ }^{33}$ are more typical, one can suppose that the remaining sites in the lutetium coordination sphere will be occupied by solvent molecules $[\mathrm{Lu}\{\mathrm{P}(\mathrm{O}), \mathrm{P}(\mathrm{O})-\mathrm{L}\}\{\mathrm{P}(\mathrm{O})-\mathbf{L}\}-$ $\left.\left(\mathrm{OO}-\mathrm{NO}_{3}\right)_{2}(\mathrm{MeCN})_{m}\right]^{+} \cdot\left(\mathrm{NO}_{3}\right)^{-}$(Scheme 6). Complex species with coordinated solvent molecules are most likely to be involved in dynamic equilibria with species containing no coordinated solvent molecules to cause signal broadening in the ${ }^{31} \mathrm{P}$ NMR spectrum.

The NMR spectra (Tables 5 and 6) agree well with the supposed structure (Scheme 6). The ${ }^{31} \mathrm{P}$ NMR shows a sole broadened signal for the phosphorus nuclei, which seems to be explained by fast exchange processes. The signal is downfield shifted by $12.6 \mathrm{ppm}$ relative to the free ligand signal. The ${ }^{1} \mathrm{H}$ and ${ }^{13} \mathrm{C}$ NMR spectra display expected changes.

Thus, in AN solutions, the lanthanum (3) and neodymium (5) complexes retain the structure revealed in the crystal. The structures of the uranyl (1), neodymium (4), and lutetium (6)

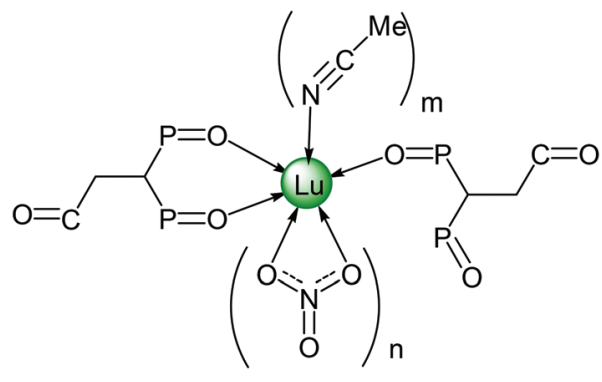

Scheme 6 Complex 6 in the solid state $(n=3, m=0)$, and complex cation of compound 6 ( $n=2, m=1$ or 2 ) in AN solution.

complexes change in solution. In the studied complexes in AN solutions, the scorpionate ligand $\mathbf{L}$ shows three coordination modes: $\mathrm{P}(\mathrm{O})$-monodentate, chelate $\mathrm{P}(\mathrm{O}), \mathrm{P}(\mathrm{O})$-bidentate, and $\mathrm{P}(\mathrm{O}), \mathrm{P}(\mathrm{O}), \mathrm{C}(\mathrm{O})$-tridentate. The uranyl (1) and lanthanum (3) complexes in AN solution are neutral, whereas the neodymium (4 and 5) and lutetium (6) complexes are cationic.

2.3.2. Chloroform solutions. In chloroform solutions, only uranyl complex 1 retains the structure revealed in the crystal, the structures of all of the other lanthanide complexes change.

Uranyl complex $\mathbf{1}$ is relatively poorly soluble in chloroform $(\sim 0.003 \mathrm{M})$, however, it has much better solubility $(\geq 0.02 \mathrm{M})$ in solution containing 3 equiv. of ligand $\mathbf{L}$. The ${ }^{31} \mathrm{P}$ NMR spectra of the $3: 1$ mixture showed at least 3 broad peaks at $45.9,45.3$ and 45.0 and one peak at $31.6 \mathrm{ppm}$ with an integral intensity ratio $\sim 2: 3$, which indicates the presence of complex species of different stoichiometry containing both $\mathrm{P}(\mathrm{O})$ - and $\mathrm{P}(\mathrm{O}), \mathrm{P}(\mathrm{O})$ coordinated ligand molecules. The position of the analytical bands in the IR spectrum of a solution of compound 1 slightly differs compared with the spectrum of the crystalline sample (Table 5). The ${ }^{31} \mathrm{P}$ NMR spectrum shows a singlet at $44.4 \mathrm{ppm}$. The ${ }^{1} \mathrm{H}$ NMR spectrum of complex 1 shows that the $\mathrm{CH}$ resonance is shifted downfield by $c a$. $-0.5 \mathrm{ppm}$ with respect to the free ligand, and the $\mathrm{CH}_{3}$ resonance is shifted downfield by ca. -0.10 and $-0.25 \mathrm{ppm}$ (Table 7 ). The proton signal of the $\mathrm{CH}$ group is broadened. The carbon signals of the indicator groups $\mathrm{C}=\mathrm{O}, \underline{\mathrm{CH}}$, and $\underline{\mathrm{CH}}_{2}$ in the ${ }^{13} \mathrm{C}$ NMR spectrum are shifted upfield relative to the free ligand signals (Table 7 ). These changes agree well with a chelating $\mathrm{P}(\mathrm{O}), \mathrm{P}(\mathrm{O})$-mode of ligand coordination. The neutral uranyl complex in chloroform solution has the structure $\left[\mathrm{UO}_{2}\{\mathrm{P}(\mathrm{O}), \mathrm{P}(\mathrm{O})-\mathrm{L}\}\left(\mathrm{OO}-\mathrm{NO}_{3}\right)_{2}\right]$.

The structure of lanthanum complex 3 in chloroform solution according to IR spectroscopic data (Table 5) differs from that in the crystal and AN solution. Both ligand molecules in complex 3 are coordinated in a $\mathrm{P}(\mathrm{O}), \mathrm{P}(\mathrm{O}), \mathrm{C}(\mathrm{O})$-tridentate mode. The bands of coordinated $\mathrm{P}=\mathrm{O}$ and $\mathrm{C}=\mathrm{O}$ groups are observed at 1173 and $1713 \mathrm{~cm}^{-1}$. The bands at 1450 and $1319 \mathrm{~cm}^{-1}$ correspond to bidentately coordinated nitrato groups. Taking into account the typical lanthanum coordination number of ten, one can suppose that complex 3 in chloroform solution is present as a contact ion pair $\left[\mathrm{La}\{\mathrm{P}(\mathrm{O}), \mathrm{P}(\mathrm{O}), \mathrm{C}(\mathrm{O})-\mathbf{L}\}_{2}\left(\mathrm{OO}-\mathrm{NO}_{3}\right)_{2}\right]^{+} \cdot\left(\mathrm{NO}_{3}\right)^{-}$(Scheme 7). 


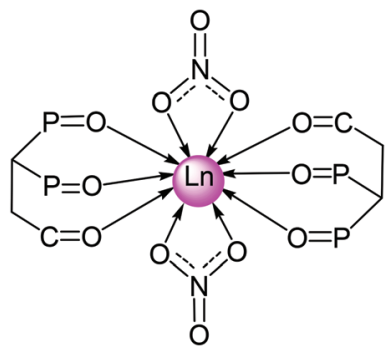

Scheme 7 Complex cations compounds $3(\mathrm{Ln}=\mathrm{La}), 4$ and $5(\mathrm{Ln}=\mathrm{Nd})$ in $\mathrm{CDCl}_{3}$ solutions.

The NMR spectra (Tables 5-7) agree well with the proposed structure. The ${ }^{31} \mathrm{P}$ NMR spectrum shows a sole broadened phosphorus signal at $36.0 \mathrm{ppm}$ shifted from the free ligand signal by $4.8 \mathrm{ppm}$. The ${ }^{1} \mathrm{H}$ NMR spectrum displays the signals of the $\mathrm{CH}_{3}, \mathrm{CH}_{2}$, and $\mathrm{CH}$ groups downfield shifted relative to the free ligand signal, the signals of the two latter groups are broadened. The largest shift is observed for the protons of the $\mathrm{CH}_{2}$ group (0.42 ppm), whereas the signals of $\mathrm{CH}_{3}$ and $\mathrm{CH}$ groups are shifted by 0.08 and $0.18 \mathrm{ppm}$. The ${ }^{13} \mathrm{C}$ NMR spectrum of complex 3 in chloroform solution exhibits considerably broadened signals for the $\mathrm{CH}_{2}, \underline{\mathrm{CH}}$, and $\underline{\mathrm{C}}=\mathrm{O}$ groups. The signals of the $\underline{\mathrm{CH}}$ and $\underline{\mathrm{C}}=\mathrm{O}$ groups have the largest shift relative to the free ligand signal: -4.3 and $2.4 \mathrm{ppm}$, respectively. The signals of the $\underline{\mathrm{CH}}_{3}$ and $\underline{\mathrm{CH}}_{2}$ groups are shifted much less: 0.36 and $0.5 \mathrm{ppm}$. Signal broadening observed for all of the NMR spectra of chloroform solutions of 3 indicate relatively fast on the NMR time scale equilibria with participation of other types of complexes (for example [La $\{\mathrm{P}(\mathrm{O}), \mathrm{P}(\mathrm{O})$ $\left.\mathbf{L}\}_{2}\left(\mathrm{OO}-\mathrm{NO}_{3}\right)_{3}\right]$ and similar species).

The spectra of neodymium complexes 4 and 5 in chloroform are identical except for the bands of solvate ethanol at 3683 and $3622 \mathrm{~cm}^{-1}$ in the spectrum of 5 . According to IR data, the structures of complexes $\mathbf{4}$ and $\mathbf{5}$ in chloroform solutions differ from those revealed in the crystalline forms and in AN solution. In chloroform solution, both ligand molecules are coordinated in a tridentate mode. The bands of coordinated $\mathrm{P}=\mathrm{O}$ groups are detected at 1173 and $1162 \mathrm{~cm}^{-1}$, those of coordinated $\mathrm{C}=\mathrm{O}$ groups are observed at $1712 \mathrm{~cm}^{-1}$. The bands at 1460 and $1313 \mathrm{~cm}^{-1}$ correspond to nitrato group vibrations. One can suppose that the neodymium bisligand complex in chloroform solution has the same structure as lanthanum complex 3: $\left[\mathrm{Nd}\{\mathrm{P}(\mathrm{O}), \mathrm{P}(\mathrm{O}), \mathrm{C}(\mathrm{O})-\mathbf{L}\}_{2}\left(\mathrm{OO}-\mathrm{NO}_{3}\right)_{2}\right]^{+}$. $\left(\mathrm{NO}_{3}\right)^{-}$(Scheme 7). The $\mathrm{CN}$ of neodymium is ten.

Paramagnetic properties of neodymium hamper the use of NMR spectroscopy to study the structure of $\mathrm{Nd}$ complexes. However, signal broadening in NMR spectra of complexes 4 and $\mathbf{5}$ is much larger than that observed for neodymium nitrate complexes with other phosphoryl-containing ligands. ${ }^{28 b-e, 34}$ Thus, the ${ }^{1} \mathrm{H}$ NMR spectrum of complex 4 , the signals of all protons either considerably broadened or not detected at all. The ${ }^{31} \mathrm{P}$ NMR spectrum shows two broad signals at 86 and $70 \mathrm{ppm}\left(W_{1 / 2}=5\right.$ and $6 \mathrm{ppm}$, respectively) with approximate ratio $8: 1$ (Table 5), which indicates the presence of equilibrium in solution of the studied complex. One can suppose that dynamic equilibria involve structural isomers with different ligand coordination modes, species differing in the number of coordinated nitrato groups or ligand molecules, intermolecular exchange processes, etc. ${ }^{13} \mathrm{C}$ NMR spectrum could not be interpreted correctly because of the presence of additional signals.

The IR spectrum of lutetium complex 6 in chloroform solution shows the bands of coordinated $\mathrm{P}=\mathrm{O}$ groups at 1162-1173 $\mathrm{cm}^{-1}$ and a shoulder at $1195 \mathrm{~cm}^{-1}$ due to the vibrations of the free $\mathrm{P}=\mathrm{O}$ group. The band at $1715 \mathrm{~cm}^{-1}$ slightly shifted relative to the free ligand band $\left(1719 \mathrm{~cm}^{-1}\right)$ corresponds to vibrations of the $\mathrm{C}=\mathrm{O}$ groups. A broad absorption at $3200 \mathrm{~cm}^{-1}$ corresponds to vibrations of coordinated water. The bands at 1490 and $1310 \mathrm{~cm}^{-1}$ are consistent with bidentately coordinated nitrato groups. In accordance with these data, one can suppose that complex 6 in chloroform solution exists as an ion pair. Both ligand molecules are coordinated through one and two phosphoryl groups, however, it is rather difficult to determine the interaction mode for the $\mathrm{C}=\mathrm{O}$ groups. One can suppose that both $\mathrm{C}=\mathrm{O}$ groups form $\mathrm{H}$-bonds with coordinated water molecules, the CN of lutetium will be eight (Scheme 8).

This type of ligand coordination is not unique. A number of complexes are known where ligands form H-bonds with coordinated water molecules rather than coordination bonds with a metal. ${ }^{35}$ The NMR spectroscopic data agree well with the suggested structure (Scheme 8). Thus, the ${ }^{31} \mathrm{P}$ NMR spectrum shows a sole signal for the phosphorus nuclei shifted by $9.1 \mathrm{ppm}$ relative to the free ligand signal $\left(W_{1 / 2}=0.5 \mathrm{ppm}\right)$ (Table 5). On cooling to $-50{ }^{\circ} \mathrm{C}$, a second broadened resonance at about $35 \mathrm{ppm}$, which may be related to an uncoordinated $\mathrm{P}(\mathrm{O})$ group,$^{36}$ appears along with the main broadened signal at $\sim 40 \mathrm{ppm}$. Fast exchange processes with participation of coordinated and uncoordinated $\mathrm{P}(\mathrm{O})$ groups seem to take place in the coordination sphere of $\mathrm{Lu}$ in complex 6 at ambient temperature.

The ${ }^{1} \mathrm{H}$ and ${ }^{13} \mathrm{C}$ NMR spectra of complex 6 (Tables 6 and 7 ) are as expected for the structure of the complex cation in Scheme 8. Thus for ${ }^{13} \mathrm{C}$, the change in the chemical shifts are $\Delta \delta_{\mathrm{C}}\left(\underline{\mathrm{CH}}_{3}\right) 0.17 \mathrm{ppm}, \Delta \delta_{\mathrm{C}}\left(\underline{\mathrm{CH}}_{2}\right) 1.11 \mathrm{ppm}, \Delta \delta_{\mathrm{C}}(\underline{\mathrm{CH}})-3.68 \mathrm{ppm}$, and $\Delta \delta_{\mathrm{C}}(\mathrm{C}=\mathrm{O}) 1.9 \mathrm{ppm}$. The signal of the $\mathrm{C}=\mathrm{O}$ group is broad. These changes are close to those observed for the spectrum of complex 3 and agree well with the conclusion of the

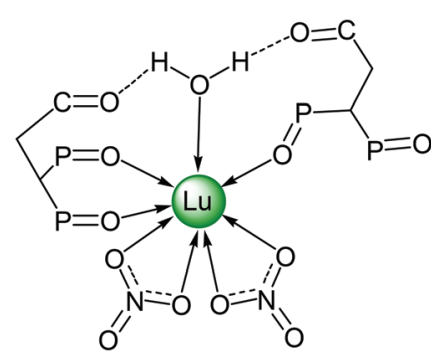

Scheme 8 Complex cation of compound 6 in $\mathrm{CDCl}_{3}$ solution. 
participation of the $\mathrm{C}=\mathrm{O}$ group in certain interactions. The changes in chemical shifts $\left(\Delta \delta_{\mathrm{H}}\right)$ for the $\mathrm{CH}_{3}$ and $\mathrm{CH}_{2}$ groups also confirm the conclusion of the involvement of the $\mathrm{C}=\mathrm{O}$ group in "coordination". The water signal in the spectrum of 6 is at $5.4 \mathrm{ppm}$, whereas it is usually detected in chloroform at $\sim 1.6 \mathrm{ppm}$.

It is possible that this complex is in equilibrium with other complexes, for example, $[\mathrm{Lu}\{\mathrm{P}(\mathrm{O}), \mathrm{P}(\mathrm{O}), \mathrm{C}(\mathrm{O})-\mathrm{L}\} \mathrm{P}(\mathrm{O}), \mathrm{C}(\mathrm{O})-\mathbf{L}\}-$ $\left.\left(\mathrm{H}_{2} \mathrm{O}\right)\left(\mathrm{OO}-\mathrm{NO}_{3}\right)_{2}\right]^{+} \cdot\left(\mathrm{NO}_{3}\right)^{-}$, where both $\mathrm{C}=\mathrm{O}$ groups are weakly coordinated to the metal $(\mathrm{CN}=10)$, neutral complex $\left[\mathrm{Lu}\{\mathrm{P}(\mathrm{O}), \mathrm{P}(\mathrm{O})-\mathrm{L}\}\{\mathrm{P}(\mathrm{O})-\mathrm{L}\}\left(\mathrm{H}_{2} \mathrm{O}\right)\left(\mathrm{OO}-\mathrm{NO}_{3}\right)_{3}\right](\mathrm{CN}=10)$, etc. However, $\mathrm{CN}=10$ is less typical for lutetium cations.

Thus, scorpionate ligand $\mathbf{L}$ in complexes with f-block element nitrates in chloroform show variable denticity. In the complex with uranyl nitrate $\mathbf{1}$, this ligand is coordinated in a $\mathrm{P}(\mathrm{O}), \mathrm{P}(\mathrm{O})$ bidentate mode like in the crystal. This kind of chelate coordination is not realized in chloroform solutions of complexes with lanthanide nitrates 3-6. The main coordination is $\mathrm{P}(\mathrm{O}), \mathrm{P}(\mathrm{O}) \mathrm{C}(\mathrm{O})$-tridentate, while $\mathrm{P}(\mathrm{O}) \mathrm{C}(\mathrm{O})$-bidentate coordination, however through $\mathrm{H}$-bond formation, is observed for the first time in the lutetium complex.

It should be noted that almost all studied complexes are labile in solution. Except for uranyl complex $\mathbf{1}$ in chloroform and AN, all other complexes have one or two broadened resonances in the ${ }^{31} \mathrm{P}$ NMR spectra (Table 5). Although we did not conduct a detailed study, we suppose that the structures shown in Schemes 4-8 and noted in the text are only the main species present in solution. Virtually all of the studied complexes exhibit fluxional behavior in solution.

Let us note that only monoligand uranyl complex $\left[\mathrm{UO}_{2}\left(\mathrm{NO}_{3}\right)_{2} \mathbf{L}\right]$ is neutral in chloroform solution, all of the studied bisligand lanthanide complexes are cationic $\left[\mathrm{Ln}\left(\mathrm{NO}_{3}\right)_{2}(\mathbf{L})_{2}\right]^{+} \cdot\left(\mathrm{NO}_{3}\right)^{-}$. This fact should be taken into account in analyzing the data on the extraction of f-block elements from nitric acid solutions into chloroform.

Thus, the coordination mode of the scorpionate ligand $\mathbf{L}$ varies with not only the requirements of the metal coordination polyhedron and complex composition, but also depending on the solvent, and shows large variation.

\subsection{Extraction studies}

The extraction ability of ligand $\mathbf{L}$ towards the f-block elements was studied by the example of the extraction of a group of lanthanides(III), as well as uranium(VI) from nitric acid solutions into $\mathrm{CHCl}_{3}$. To compare the efficiency and selectivity of the studied ligand $\mathbf{L}$ and well-known extractant $\mathbf{L}^{\prime}$, we compared the distribution ratios of the f-block elements $(D=$ $\left.[\mathrm{M}]_{\text {org }} /[\mathrm{M}]_{\mathrm{aq}}\right)$ for both extractants under the same experimental conditions (Fig. 9, Table S2, ESI†े).

Fig. 9 shows that both compounds extract U(vi) much more efficiently than lanthanides. However, scorpionate ligand $\mathbf{L}$ extracts uranium by a factor of 6 more efficiently than its prototype $\mathbf{L}^{\prime}$. The fraction extracted for uranium over one step is $98 \%$. Let us note that the values of $\mathrm{D}_{\mathrm{U}}$ for common extractants - $(\mathrm{BuO})_{3} \mathrm{P}(\mathrm{O}),\left(\mathrm{C}_{8} \mathrm{H}_{17}\right)_{3} \mathrm{P}(\mathrm{O})$, and $\mathrm{Ph}_{2} \mathrm{P}(\mathrm{O}) \mathrm{CH}_{2} \mathrm{C}(\mathrm{O}) \mathrm{NBu}_{2}$ - is lower by 1.0 under the same experimental conditions. Com-

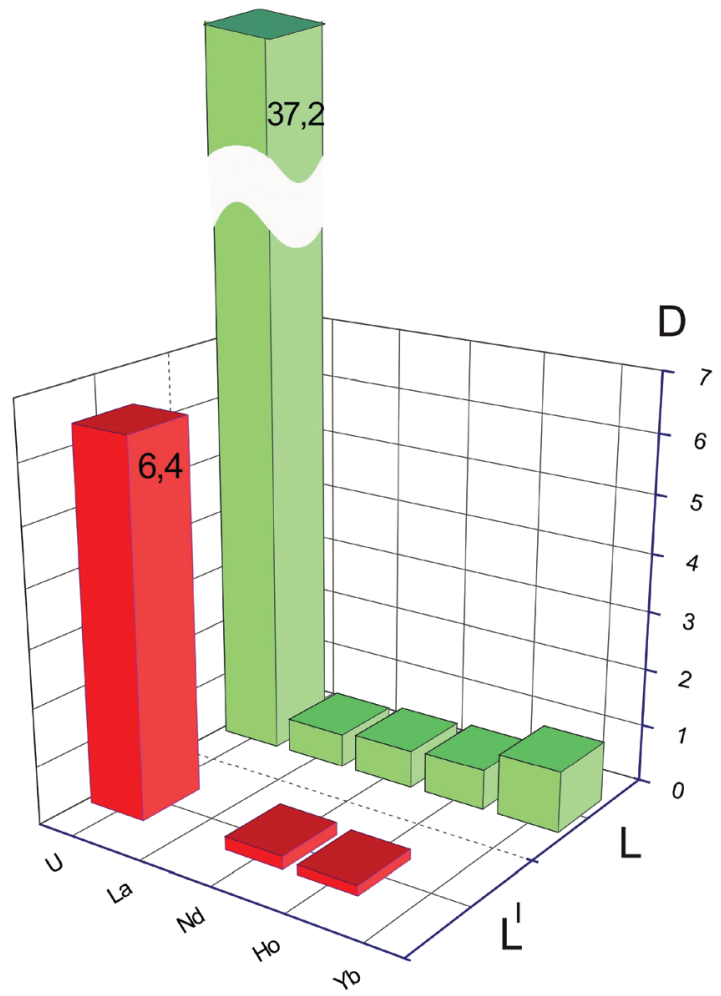

Fig. 9 Comparison of the distribution ratios of $\mathrm{U}(\mathrm{VI}), \mathrm{La}(\mathrm{III}), \mathrm{Nd}(\mathrm{III}), \mathrm{Ho}(\mathrm{III})$, and $\mathrm{Yb}(\mathrm{III})$ for the extraction with ligands $\mathrm{L}$ and $\mathrm{L}^{\prime}(0.01 \mathrm{M}$ solutions in $\mathrm{CHCl}_{3}$ ) from $3.75 \mathrm{M} \mathrm{HNO}_{3}$; the initial concentration of lanthanide and uranyl nitrates in the aqueous phase is $2.5 \times 10^{-4} \mathrm{M}$.

pound $\mathbf{L}$ is also better (about 3 times) at extracting lanthanides than ligand $\mathbf{L}^{\prime}$. The extraction selectivity $\mathrm{U}(\mathrm{vI}) / \mathrm{Ln}(\mathrm{III})$ of ligand $\mathbf{L}$ is higher than that of ligand $\mathbf{L}^{\prime}$.

As noted above, both ligands, $\mathbf{L}$ and $\mathbf{L}^{\prime}$, form crystalline complexes of the same composition with uranyl and lanthanide nitrates with the same chelate coordination of the phosphoryl groups. The $\pi$-stacking interaction between the $\mathrm{Ph}$ fragments of coordinated ligand molecules is inherent in not only ligand $\mathbf{L}$ but also to a lesser extent in ligand $\mathbf{L}^{\prime}$ (section 2.2.2). At the same time, the $\mathrm{C}=\mathrm{O}$ group of scorpionate $\mathbf{L}$ in chloroform solutions of all of the lanthanide complexes participates in coordination along with two phosphoryl groups (section 2.3.2). Judging from the spectral and X-ray diffraction data, the $\mathrm{C}=\mathrm{O} \rightarrow$ Ln bond in the studied complexes is rather weak; however, we believe that it is its formation that leads to the better extraction of lanthanides with ligand $\mathbf{L}$. It should also be noted that lanthanide complexes 3-6 in chloroform solution are ionic in contrast to neutral uranyl complex $\mathbf{1}$, which also favors the better extraction of the latter. In uranyl complex 1 , the $\mathrm{C}=\mathrm{O}$ group is not coordinated, however, it is available for other interactions. In the crystal, the uncoordinated $\mathrm{C}=\mathrm{O}$ group participates in various $\mathrm{CH} \cdots \mathrm{O}=\mathrm{C}$ contacts and one can expect that its availability for interaction with diluent will favor better extraction of the corresponding compound. 
Thus, the modification of methylene dioxide $\mathbf{L}^{\prime}$ by the introduction of a $\mathrm{MeC}(\mathrm{O}) \mathrm{CH}_{2}-$ substituent leads to a considerable improvement in the extraction properties of the hybrid scorpionate ligand $\mathbf{L}$ toward f-block elements.

\section{Conclusion}

Coordination properties of the neutral organophosphorus scorpionate ligand $\mathbf{L}$ toward f-block elements were examined. Mono- and binuclear complexes of $\mathbf{L}$ with uranyl and lanthanide(III) nitrates were studied in the solid state (X-ray, IR) and solution (IR, ${ }^{31} \mathrm{P}$ NMR, ${ }^{13} \mathrm{C}$ NMR, and ${ }^{1} \mathrm{H}$ NMR). In the studied complexes, ligand $\mathbf{L}$ exhibits variable denticity: PO,PO-, PO,PO, CO-, PO,CO-, and PO-. The $\mathrm{C}=\mathrm{O} \rightarrow$ Ln coordination bond is rather weak; at the same time, the noncoordinated $\mathrm{C}=\mathrm{O}$ group is involved in weak noncovalent interactions in both solution and in the crystalline form. Ligand coordination mode and complex structure are readily variable depending on both the nature of the metal and interactions in the second coordination sphere. The extraction experiments revealed an expected increase in the affinity of scorpionate ligand $\mathbf{L}$ over its unmodified prototype $\mathbf{L}^{\prime}$ for studied metal ions.

\section{Experimental}

\subsection{General}

Solvents were purified and dried using standard procedures. Deuterated solvents, $\mathrm{CD}_{3} \mathrm{CN}(99.8 \% \mathrm{D}$, Sigma-Aldrich) and $\mathrm{CDCl}_{3}$ (99.8\% D, Sigma-Aldrich), were used as received. Multinuclear NMR spectra were recorded on a Bruker Avance 400 spectrometer, operating frequency $400.23 \mathrm{MHz}\left({ }^{1} \mathrm{H}\right.$ and ${ }^{1} \mathrm{H}$ $\left.\left\{{ }^{31} \mathrm{P}\right\}\right), 100.61 \mathrm{MHz}\left({ }^{13} \mathrm{C}\right)$ and $161.98 \mathrm{MHz}\left({ }^{31} \mathrm{P}\right.$ and $\left.{ }^{31} \mathrm{P}\left\{{ }^{1} \mathrm{H}\right\}\right)$ at ambient temperature using $\mathrm{CD}_{3} \mathrm{CN}$ or $\mathrm{CDCl}_{3}$ solution $(0.01 \mathrm{M})$, unless otherwise stated. Chemical shifts ( $\mathrm{ppm}$ ) refer to the residual protic solvent peaks (for ${ }^{1} \mathrm{H}$ and ${ }^{13} \mathrm{C}$ ), and $85 \% \mathrm{H}_{3} \mathrm{PO}_{4}$ (for ${ }^{31} \mathrm{P}$ ) as external standards and coupling constants are expressed in hertz $(\mathrm{Hz})$, the band width at half-height $\left(W_{1 / 2}\right)$ in ppm (for ${ }^{31} \mathrm{P}\left\{{ }^{1} \mathrm{H}\right\}$ NMR spectra). IR spectra in the region 400-4000 $\mathrm{cm}^{-1}$ were obtained on a Bruker Tensor 37 FTIR spectrometer. The samples were $\mathrm{KBr}$ pellets, mulls in Nujol and hexachlorobutadiene as well as $0.01 \mathrm{M}$ solutions $\left(\mathrm{CD}_{3} \mathrm{CN}\right.$, $\mathrm{CDCl}_{3}$ ) in $\mathrm{CaF}_{2}$ cuvettes, unless otherwise stated. Raman spectra of the solid samples were obtained in the region 100-3500 $\mathrm{cm}^{-1}$ using a Jobin-Yvon LabRAM 300 laser Raman spectrometer with $632.8 \mathrm{~nm}$ excitation of $2 \mathrm{~mW}$ output power. Elemental analyses were performed at the Laboratory of Microanalysis, INEOS RAS.

The reagents (E)-4-(Diphenylphosphoryl)but-3-en-2-one ${ }^{12}$ and methylenediphosphine dioxide $\left(\mathbf{L}^{\prime}\right)^{37}$ were prepared according to literature procedures. Chlorodiphenylphosphine (Acros) was purified by vacuum distillation immediately prior to use. Glacial acetic acid (reagent grade) was distilled before reaction. Basic Brockmann activity grade $\mathrm{I} \mathrm{Al}_{2} \mathrm{O}_{3}, 50-200 \mu \mathrm{m}$ (Acros) and silica gel 130-270 mesh, $60 \AA$ A (Aldrich) were used.
Acetonitrile was dried by distillation over $\mathrm{P}_{2} \mathrm{O}_{5}$ prior to use. All manipulations with chlorodiphenylphosphine were carried out under an argon atmosphere.

The following reagents were used for the preparation of solutions in the extraction study: bidistilled water, $\mathrm{CHCl}_{3}$ (reagent grade), arsenazo III (analytical grade), $\mathrm{HNO}_{3}$ (high purity grade), $\mathrm{UO}_{2}\left(\mathrm{NO}_{3}\right)_{2} \cdot 6 \mathrm{H}_{2} \mathrm{O}$ (reagent grade), $\mathrm{La}\left(\mathrm{NO}_{3}\right)_{3} \cdot 6 \mathrm{H}_{2} \mathrm{O}$ (reagent grade), $\mathrm{Nd}\left(\mathrm{NO}_{3}\right)_{3} \cdot 6 \mathrm{H}_{2} \mathrm{O}$ (reagent grade), Ho $\left(\mathrm{NO}_{3}\right)_{3} \cdot 6 \mathrm{H}_{2} \mathrm{O}$ (pure grade), and $\mathrm{Yb}\left(\mathrm{NO}_{3}\right)_{3} \cdot 6 \mathrm{H}_{2} \mathrm{O}$ (pure grade). Solutions for spectral and extraction studies were prepared by volumetric/gravimetric method.

4.1.1 Synthesis of 4,4-bis(diphenylphosphoryl)butan-2-one (L). A solution of $0.250 \mathrm{~g}$ ( $3.85 \mathrm{mmol})$ of glacial acetic acid in $3 \mathrm{~mL}$ of anhydrous acetonitrile and next a solution of $0.793 \mathrm{~g}$ (3.6 mmol) of $\mathrm{Ph}_{2} \mathrm{PCl}$ in $4 \mathrm{~mL}$ of anhydrous acetonitrile were added dropwise to a solution of $0.81 \mathrm{~g}(3 \mathrm{mmol})$ of $(E)-4$ (diphenylphosphoryl)but-3-en-2-one in $8 \mathrm{~mL}$ of anhydrous acetonitrile, the reaction mixture was kept for $48 \mathrm{~h}$ at ambient temperature, after which the solvent was removed under vacuum ( $\sim 10$ Torr) at ambient temperature. The resulting oily residue was kept for $2 \mathrm{~h}$ at $55{ }^{\circ} \mathrm{C}$ at $\sim 1$ Torr, dissolved in $15 \mathrm{~mL}$ of $\mathrm{CH}_{2} \mathrm{Cl}_{2}$, and the resultant solution was sequentially filtered through $3 \mathrm{~g}$ of basic alumina and $1.5 \mathrm{~g}$ of silica gel, with washing of each sorbent with $15 \mathrm{ml}$ of $\mathrm{CH}_{2} \mathrm{Cl}_{2}$. The filtrate was evaporated to dryness, and the resultant foam-like residue was crystallized from benzene and dried under vacuum ( $\sim 1$ Torr) at $120{ }^{\circ} \mathrm{C}$ until a constant weight to give $\mathbf{L}$ (0.595 g, 42.1\%). Mp 146.5-148.0 ${ }^{\circ} \mathrm{C}$ (lit. ${ }^{10} 145.0-145.5{ }^{\circ} \mathrm{C}$ ). Found: $\mathrm{C}, 71.23 ; \mathrm{H}, 5.44 ; \mathrm{P}$, 13.13. Calc. For $\mathrm{C}_{28} \mathrm{H}_{26} \mathrm{O}_{3} \mathrm{P}_{2}$ : C, 71.18; H, 5.55; P, 13.11\%. IR (KBr disk): $\nu_{\max } / \mathrm{cm}^{-1} 1720 \mathrm{~s}$ $(\mathrm{C}=\mathrm{O}), 1202 \mathrm{~s}$ and $1182 \mathrm{~s}(\mathrm{P}=\mathrm{O}) .{ }^{1} \mathrm{H}$ NMR (400 $\mathrm{MHz}, \mathrm{CDCl}_{3}$, $0.1 \mathrm{M}): \delta 1.54\left(3 \mathrm{H}, \mathrm{s}, \mathrm{CH}_{3},\right), 2.94\left(2 \mathrm{H}, \mathrm{dt},{ }^{3} J_{\mathrm{HH}} 5.3,{ }^{3} J_{\mathrm{HP}} 14.5\right.$, $\left.\mathrm{CH}_{2}\right), 4.45\left(1 \mathrm{H}, \mathrm{tt},{ }^{3} J_{\mathrm{HH}} 5.2,{ }^{2} J_{\mathrm{HP}} 14.3, \mathrm{CH}\right), 7.23-7.31(8 \mathrm{H}, \mathrm{m}$, $m-\mathrm{Ph}), 7.31-7.38(4 \mathrm{H}, \mathrm{m}, p-\mathrm{Ph}), 7.64-7.73(4 \mathrm{H}, \mathrm{m}, o-\mathrm{Ph})$, 7.76-7.85 (4H, m, o-Ph). ${ }^{1} \mathrm{H}\left\{{ }^{31} \mathrm{P}\right\}$ NMR (400 $\mathrm{MHz}, \mathrm{CDCl}_{3}$, $0.1 \mathrm{M}): \delta 1.55\left(3 \mathrm{H}, \mathrm{s}, \mathrm{CH}_{3}\right), 2.94\left(2 \mathrm{H}, \mathrm{d},{ }^{3} \mathrm{~J}_{\mathrm{HH}} 5.0, \mathrm{CH}_{2}\right), 4.46$ $\left(1 \mathrm{H}, \mathrm{t},{ }^{3} \mathrm{~J}_{\mathrm{HH}} 5.1, \mathrm{CH}\right), 7.23-7.31(8 \mathrm{H}, \mathrm{m}, m-\mathrm{Ph}), 7.31-7.39(4 \mathrm{H}$, $\mathrm{m}, p-\mathrm{Ph}), 7.68\left(4 \mathrm{H}, \mathrm{d},{ }^{3} J_{\mathrm{HH}} 7.7, o-\mathrm{Ph}\right), 7.81\left(4 \mathrm{H}, \mathrm{d},{ }^{3} J_{\mathrm{HH}} 7.3\right.$, $o$-Ph). ${ }^{13} \mathrm{C}\left\{{ }^{1} \mathrm{H}\right\}$ NMR (100.61 MHz, $\left.\mathrm{CDCl}_{3}, 0.1 \mathrm{M}\right): \delta 28.81$ $\left(\mathrm{s}, \mathrm{CH}_{3}\right), 36.73\left(\mathrm{t},{ }^{1} J_{\mathrm{CP}} 59.4, \mathrm{CH}\right), 38.70\left(\mathrm{~s}, \mathrm{CH}_{2}\right), 128.10$ (d, $\left.{ }^{3} J_{\mathrm{CP}} 12.5, m-\mathrm{Ph}\right), 128.12\left(\mathrm{~d},{ }^{3} J_{\mathrm{CP}} 12.5, m-\mathrm{Ph}\right), 130.82$ (d, ${ }^{1} J_{\mathrm{CP}} 103.0$, ipso-Ph), 131.33 (dd, ${ }^{1} J_{\mathrm{CP}} 100.6,{ }^{3} J_{\mathrm{CP}}=3.0$, ipso$\mathrm{Ph}), 131.45-131.53$ (m, $p$-Ph), 131.48 (d, $\left.{ }^{2} J_{\mathrm{CP}} 9.8, o-\mathrm{Ph}\right), 131.52$ $\left(\mathrm{d},{ }^{2} J_{\mathrm{CP}} 10.1, o-\mathrm{Ph}\right), 131.63-131.71(\mathrm{~m}, p-\mathrm{Ph}), 203.84\left(\mathrm{t},{ }^{3} J_{\mathrm{CP}} 4.9\right.$, $\mathrm{C}=\mathrm{O}) .{ }^{31} \mathrm{P}\left\{{ }^{1} \mathrm{H}\right\}$ NMR (161.98 MHz, $\left.\mathrm{CDCl}_{3}, 0.1 \mathrm{M}\right): \delta 31.25(\mathrm{~s})$.

4.1.2 Synthesis of complexes 1 and 3-6 (general). The complexes $\mathbf{1}$ and 3-6, including those suitable for X-ray analysis, were prepared according to a similar procedure, with a ratio of reagents of $1: 1$ or $1: 2$. The yields were $50-90 \%$, but no attempts were made to optimize the yield for each individual complex.

4.1.3 $\left[\mathrm{UO}_{2}\left(\mathrm{NO}_{3}\right)_{2} \mathbf{L}\right]$, 1. (a) A solution of $\mathrm{UO}_{2}\left(\mathrm{NO}_{3}\right)_{2} \cdot 6 \mathrm{H}_{2} \mathrm{O}$ $(106.2 \mathrm{mg}, 0.212 \mathrm{mmol})$ in acetonitrile $(1 \mathrm{~mL})$ was added dropwise to a stirred solution of ligand $\mathbf{L}(100.0 \mathrm{mg}, 0.212 \mathrm{mmol})$ in chloroform $(1 \mathrm{~mL})$ at room temperature. The resulting yellow precipitate was collected by filtration, washed with 
diethyl ether, and dried in vacuo (1 Torr) at $62{ }^{\circ} \mathrm{C}$ to give 1 (167.4 mg, 91\%).

(b) A solution of $\mathrm{UO}_{2}\left(\mathrm{NO}_{3}\right)_{2} \cdot 6 \mathrm{H}_{2} \mathrm{O}(35.1 \mathrm{mg}, 0.070 \mathrm{mmol})$ in acetonitrile $(1.5 \mathrm{~mL})$ was added dropwise to a stirred solution of ligand $\mathbf{L}$ (100.0 $\mathrm{mg}, 0.212 \mathrm{mmol}$ ) in chloroform $(1 \mathrm{~mL})$ at room temperature. The transparent light yellow solution was concentrated at $\sim 60{ }^{\circ} \mathrm{C}$ in vacuo ( $\sim 5$ Torr) down to volume of $\sim 1 \mathrm{~mL}$. Light yellow transparent crystals of 1 , including those suitable for X-ray diffraction studies, were obtained under cooling to room temperature. The resulting yellow crystals were collected by filtration, washed with diethyl ether, and dried in air at r.t. to give 1 (30.0 mg, 50\%). Mp 235-236 ${ }^{\circ} \mathrm{C}$. Found: C, 38.56; H, 3.05; N, 3.01; P, 7.31; U, 27.89. Calc. for $\mathrm{C}_{28} \mathrm{H}_{26} \mathrm{~N}_{2} \mathrm{O}_{11} \mathrm{P}_{2} \mathrm{U}$ : C, 38.81; H, 3.02; N, 3.23; P, 7.15; U, 27.47\%. IR (KBr disk): $\nu_{\max } / \mathrm{cm}^{-1} 1720 \mathrm{~s}(\mathrm{C}=\mathrm{O}), 1166 \mathrm{~s}(\mathrm{P}=\mathrm{O}), 1518 \mathrm{~s}$ $(\mathrm{N}=\mathrm{O}), \quad 1308 \mathrm{~s}$ and $1282 \mathrm{~s} \quad\left(\mathrm{NO}_{2}\right)_{\mathrm{as}}, 1032 \mathrm{w} \quad\left(\mathrm{NO}_{2}\right)_{\mathrm{s}}, 939 \mathrm{~s}$ $(\mathrm{O}=\mathrm{U}=\mathrm{O})_{\text {as }}$.

Raman: $\nu / \mathrm{cm}^{-1} 858(\mathrm{O}=\mathrm{U}=\mathrm{O})_{\text {as }}, 1037\left(\mathrm{NO}_{2}\right)_{\mathrm{s}} \cdot{ }^{1} \mathrm{H} \mathrm{NMR}$ (400.13 MHz, $\left.\mathrm{CDCl}_{3}, \sim 0.003 \mathrm{M}\right): \delta 1.38$ (3H, s, Me), $2.85(2 \mathrm{H}, \mathrm{d}$. t., $\left.{ }^{3} J_{\mathrm{HH}} 5.0,{ }^{3} J_{\mathrm{HP}} 14.7, \mathrm{CH}_{2}\right), 4.96(1 \mathrm{H}$, br m., CH), 7.18-7.22 (4H, m, m-Ph); 7.34-7.38 (2H, m, p-Ph); 7.63-7.68 (6H, m, $m+$ $p$-Ph); $7.84-7.89$ (4H, m, o-Ph); $8.14-8.19$ (4H, m, o-Ph). ${ }^{13} \mathrm{C}$ $\left\{{ }^{1} \mathrm{H}\right\} \mathrm{NMR}\left(100.61 \mathrm{MHz}, \mathrm{CDCl}_{3}, \sim 0.003 \mathrm{M}\right): \delta 28.84\left(\mathrm{~s}, \mathrm{CH}_{3}\right)$, $31.93(\mathrm{~s}, \mathrm{CH}), 37.72\left(\mathrm{~s}, \mathrm{CH}_{2}\right), 129.10-129.40(\mathrm{~m}, \mathrm{Ph})$, 129.71-129.95 (m, Ph), 130.95-131.05 (m, Ph), 131.10-131.28 (m, Ph), 133.44 (s, Ph), 134.14 (s, Ph), 202.42s (s, C=O). No signals of ipso-Ph were observed. ${ }^{31} \mathrm{P}\left\{{ }^{1} \mathrm{H}\right\}$ (161.98 $\mathrm{MHz}, \mathrm{CDCl}_{3}$, $\sim 0.003 \mathrm{M}): \delta 44.4\left(\mathrm{~s}, \mathrm{~W}_{1 / 2} 0.03\right)$.

4.1.4 $\left[\left\{\mathbf{U O}_{2}\left(\mathrm{NO}_{3}\right) \mathbf{L}\right\}_{2}\left(\boldsymbol{\mu}_{2}-\mathbf{O}_{2}\right)\right] \cdot \mathbf{E t O H}, 2$. Dissolution of a precipitate of $\mathbf{1}$ in $\mathrm{EtOH}$ under heating led to the formation of a clear yellow solution. The solution was left to stand in ambient light for 4 weeks and produced by slow isothermal evaporation, yellow solid and yellow crystalline material. Only a small number of crystals were yielded, and some of these proved to be suitable for single-crystal X-ray diffraction. Elemental analysis and vibrational spectra could not be obtained because of the low yield of 2 .

4.1.5 $\left[\mathrm{La}\left(\mathrm{NO}_{3}\right)_{3} \mathrm{~L}_{2}\right] \cdot 2.33 \mathrm{MeCN}, \quad 3 . \mathrm{A}$ solution of $\mathrm{La}$ $\left(\mathrm{NO}_{3}\right)_{3} \cdot 6 \mathrm{H}_{2} \mathrm{O}(40.2 \mathrm{mg}, 0.09 \mathrm{mmol})$ in acetonitrile $(2 \mathrm{~mL})$ was added dropwise to a stirred solution of ligand $\mathbf{L}(87.7 \mathrm{mg}$, $0.18 \mathrm{mmol})$ in chloroform $(0.5 \mathrm{~mL})$ at room temperature. After addition of ten drops of anhydrous ether, a white precipitate formed, it was dissolved by addition of $1 \mathrm{~mL}$ of acetonitrile. After a while, a large amount of fine white needle-like crystals formed, some of them were suitable for X-ray diffraction study. The crystals were separated by decantation, washed with anhydrous ether and dried in air (108.5 mg, 81\%). Mp (with decomp.) $153-159{ }^{\circ} \mathrm{C}$. The elemental analysis indicated that the formula of crystals of 3 is $\mathrm{La}\left(\mathrm{NO}_{3}\right)_{3} \cdot(\mathrm{L})_{2} \cdot 2 \mathrm{CH}_{3} \mathrm{CN}$. Found: $\mathrm{C}$, 53.20; H, 4.40; N, 5.01. Calc. for $\mathrm{C}_{60} \mathrm{H}_{58} \mathrm{LaN}_{5} \mathrm{O}_{15} \mathrm{P}_{4}: \mathrm{C}, 53.30 ; \mathrm{H}$, 4.32 ; N, $5.18 \%$. In the sample used to obtain the ${ }^{1} \mathrm{H}$ NMR spectrum, the presence of only two acetonitrile molecules was found. The IR band and Raman lines of the acetonitrile molecules were not observed in the vibrational spectra of 3 . IR $(\mathrm{KBr}$ disk): $\nu_{\max } / \mathrm{cm}^{-1} 1716 \mathrm{~s}(\mathrm{C}=\mathrm{O}), 1166 \mathrm{~s}(\mathrm{P}=\mathrm{O}), 1458 \mathrm{~s}(\mathrm{~N}=\mathrm{O})$, 1313s $\left(\mathrm{NO}_{2}\right)_{\text {as }}, 1031 \mathrm{w}\left(\mathrm{NO}_{2}\right)_{\mathrm{s}} \cdot{ }^{1} \mathrm{H} \mathrm{NMR}\left(400.13 \mathrm{MHz}, \mathrm{CDCl}_{3}\right)$ : $\delta 1.62\left(3 \mathrm{H}, \mathrm{s}, \mathrm{CH}_{3}\right), 3.36\left(2 \mathrm{H}, \mathrm{v}\right.$ br t, $\left.\mathrm{CH}_{2}\right), 4.63(1 \mathrm{H}, \mathrm{v}$ br s, $\mathrm{CH})$, 7.16-7.23 (4H, m, m-Ph), 7.24-7.30 (2H, m, $p$-Ph), 7.42-7.56 $(6 \mathrm{H}, \mathrm{m}, m+p-\mathrm{Ph}), 7.82-8.00(8 \mathrm{H}, \mathrm{br} \mathrm{m}, o-\mathrm{Ph})$, and $2.03(6 \mathrm{H}, \mathrm{s}$, $\left.\mathrm{CH}_{3} \mathrm{CN}\right) .{ }^{13} \mathrm{C}\left\{{ }^{1} \mathrm{H}\right\}$ NMR (100.61 MHz, $\left.\mathrm{CDCl}_{3}\right): \delta 29.17\left(\mathrm{~s}, \mathrm{CH}_{3}\right)$, 32.4 (br s, CH), 39.2 (br s, $\mathrm{CH}_{2}$ ), 128.65 (d, ${ }^{1} J_{\mathrm{CP}}$ 92.0, ipso-Ph), 128.86 (d, ${ }^{1} J_{\mathrm{CP}}$ 91.0, ipso-Ph), 128.70-129.70 (m, $m$-Ph), 131.12 (br s, o-Ph), 132.49 (s, p-Ph), $133.02(\mathrm{~s}, p-\mathrm{Ph}), 206.2$ (br s, $\mathrm{C}=\mathrm{O}$ ), and 1.92 (s, $\left.\mathrm{CH}_{3} \mathrm{CN}\right), 116.4$ (s, $\left.\mathrm{CH}_{3} \mathrm{CN}\right) .{ }^{31} \mathrm{P}\left\{{ }^{1} \mathrm{H}\right\} \mathrm{NMR}$ $\left(161.98 \mathrm{MHz}, \mathrm{CDCl}_{3}\right): \delta 36.0$ (br s, $W_{1 / 2} 0.7$ ).

4.1.6 $\left[\mathrm{Nd}\left(\mathrm{NO}_{3}\right)_{3} \mathrm{~L}_{2}\right] \cdot 3 \mathrm{MeCN}, \quad$ 4. A solution of $\mathrm{Nd}$ $\left(\mathrm{NO}_{3}\right)_{3} \cdot 6 \mathrm{H}_{2} \mathrm{O}(46.4 \mathrm{mg}, 0.106 \mathrm{mmol})$ in acetonitrile $(1 \mathrm{~mL})$ was added dropwise to a stirred solution of ligand $\mathbf{L}(100 \mathrm{mg}$, $0.212 \mathrm{mmol})$ in chloroform $(0.5 \mathrm{~mL})$ at room temperature. The solution was concentrated at $\sim 60^{\circ} \mathrm{C}$ in vacuo ( $\sim 5$ Torr) down to volume of $\sim 0.5 \mathrm{~mL}$. Overnight, a light lilac fine-crystalline precipitate of 4 (94.5 $\mathrm{mg}, 70 \%)$ formed and was filtered, washed by diethyl ether and dried in air. Mp (with decomp.) $147-150{ }^{\circ} \mathrm{C}$. Found: C, 53.15; H, 4.30; N, 5.81. Calc. for $\mathrm{C}_{62} \mathrm{H}_{61} \mathrm{~N}_{6} \mathrm{NdO}_{15} \mathrm{P}_{4}$ : C, 53.25; H, 4.40; N, 6.01\%. On storage in air, especially upon trituration, the complex easily loses solvent of crystallization. ${ }^{31}$ IR ( $\mathrm{KBr}$ disk): $\nu_{\max } / \mathrm{cm}^{-1} 1717 \mathrm{~s}$ $(\mathrm{C}=\mathrm{O}), 1164 \mathrm{~s}$ br $(\mathrm{P}=\mathrm{O}), 1465(\mathrm{~N}=\mathrm{O}), 1306 \mathrm{~s}\left(\mathrm{NO}_{2}\right)_{\mathrm{as}}, 1030 \mathrm{w}$ $\left(\mathrm{NO}_{2}\right)_{\mathrm{s}} \cdot{ }^{1} \mathrm{H}$ NMR $\left(400.13 \mathrm{MHz}, \mathrm{CD}_{3} \mathrm{CN}\right): \delta 1.10\left(3 \mathrm{H}\right.$, br s, $\left.\mathrm{CH}_{3}\right)$, $4.1\left(2 \mathrm{H}, \mathrm{v}\right.$ br s, $\left.\mathrm{CH}_{2}\right), 7.04$ (5H, br s, Ph), 7.31 (3H, br s, Ph), 7.67-7.83 (8H, br m, Ph), 8.82 (4H, v br s, Ph). No signal of $\mathrm{CH}$ was observed. ${ }^{13} \mathrm{C}\left\{{ }^{1} \mathrm{H}\right\}$ NMR (100.61 MHz, $\left.\mathrm{CD}_{3} \mathrm{CN}\right): \delta 28.30(\mathrm{~s}$, $\mathrm{CH}_{3}$ ), 29.9 (br s, CH), 39.3 (br s, $\mathrm{CH}_{2}$ ), 128.90 (d, ${ }^{3} J_{\mathrm{CP}} 12.5, \mathrm{Ph}$ ), 129.79 (d, $\left.{ }^{3} J_{\mathrm{CP}} 12.5, \mathrm{Ph}\right), 131.62-131.90$ (br m, Ph), 132.58 (br d, $\left.{ }^{2} J_{\mathrm{CP}} 8.8, \mathrm{Ph}\right), 133.01$ (s, Ph), 133.66 (s, Ph), 205.4 (br s, $\mathrm{C}=\mathrm{O})$. No signals of ipso-Ph were observed.

${ }^{31} \mathrm{P}\left\{{ }^{1} \mathrm{H}\right\}\left(161.98 \mathrm{MHz}, \mathrm{CD}_{3} \mathrm{CN}\right): \delta 86$ (br s, $\left.W_{1 / 2} 2.5\right)$.

4.1.7 $\left[\mathbf{N d}\left(\mathrm{NO}_{3}\right)_{3} \mathbf{L}_{2}\right]$ EtOH, 5. Complex $4(40 \mathrm{mg})$ was dried in vacuo ( $\sim 1$ Torr) at $62{ }^{\circ} \mathrm{C}$ and dissolved in $\sim 0.7 \mathrm{ml} \mathrm{EtOH}$. After a few days, a light lilac fine-crystalline precipitate of $\mathbf{5}$ was formed and filtered, washed by diethyl ether and dried in air (31 mg, 78\%). Mp (with decomp.) 157-160 C. Found: C, 52.62; $\mathrm{H}, 4.34 ; \mathrm{N}, 3.21$. Calc. for $\mathrm{C}_{58} \mathrm{H}_{58} \mathrm{~N}_{3} \mathrm{NdO}_{16} \mathrm{P}_{4}$ : C, 52.73; $\mathrm{H}, 4.42 ; \mathrm{N}, 3.18 \%$. IR (KBr disk): $\nu_{\max } / \mathrm{cm}^{-1} 1711$ and $1722 \mathrm{sh}$ $(\mathrm{C}=\mathrm{O}), 1160 \mathrm{~s}$ and $1150 \mathrm{~m}(\mathrm{P}=\mathrm{O}), 1503,1465(\mathrm{~N}=\mathrm{O}), 1285$, $1306\left(\mathrm{NO}_{2}\right)_{\text {as }}, 1030 \mathrm{w}\left(\mathrm{NO}_{2}\right)_{\mathrm{s}}, 1300-1500$ wide absorption $\left(\mathrm{NO}_{3}\right.$, see section 2.2.3), $3440 \mathrm{br}(\mathrm{OH})$. NMR spectra of complex 5 are identical to those of complex 4 except for the signals of solvent of crystallization in the ${ }^{1} \mathrm{H}$ and ${ }^{13} \mathrm{C}$ NMR spectra.

4.1.8 $\left[\mathrm{Lu}\left(\mathrm{NO}_{3}\right)_{3} \mathbf{L}_{2}\right]$ 6. A solution of $\mathrm{Lu}\left(\mathrm{NO}_{3}\right)_{3} \cdot 3 \mathrm{H}_{2} \mathrm{O}$ (43.9 $\mathrm{mg}, 0.106 \mathrm{mmol})$ in acetonitrile $(1 \mathrm{~mL})$ was added dropwise to a stirred solution of ligand $\mathbf{L}(100 \mathrm{mg}, 0.212 \mathrm{mmol})$ in chloroform ( $1 \mathrm{~mL})$ at room temperature. The solution was concentrated at $\sim 60{ }^{\circ} \mathrm{C}$ in vacuo ( $\sim 5$ Torr) down to volume of $\sim 0.5 \mathrm{~mL}$. After the addition of six drops of anhydrous ether, the solution became slightly turbid. Overnight, a white powder of 6 (94.5 mg, 70\%) formed and was filtered, washed by diethyl ether and dried in vacuo ( 1 Torr) at $62^{\circ} \mathrm{C}$. Mp (with decomp.) $147-150{ }^{\circ} \mathrm{C}$. Found: C, 51.33; H, 3.95; N, 3.26. Calc. for $\mathrm{C}_{56} \mathrm{H}_{52} \mathrm{LuN}_{3} \mathrm{O}_{15} \mathrm{P}_{4}$ : C, 51.51; H, 4.01; N, 3.22\%. IR (KBr disk): $\nu_{\max } / \mathrm{cm}^{-1} 1721 \mathrm{~s}(\mathrm{C}=\mathrm{O}), 1161 \mathrm{~s}$ and $1185 \mathrm{~m}(\mathrm{P}=\mathrm{O}), 1494 \mathrm{~s}$ and $1518 \mathrm{sh}(\mathrm{N}=\mathrm{O}), 1310 \mathrm{~s}\left(\mathrm{NO}_{2}\right)_{\mathrm{as}}, 1030 \mathrm{w}\left(\mathrm{NO}_{2}\right)_{\mathrm{s}}, 3200$ br $(\mathrm{OH})$. 
${ }^{1} \mathrm{H}$ NMR (400.13 MHz, $\left.\mathrm{CDCl}_{3}\right): \delta 1.61\left(3 \mathrm{H}, \mathrm{s}, \mathrm{CH}_{3}\right), 3.28(2 \mathrm{H}, \mathrm{t}$, $\left.{ }^{2} J_{\mathrm{HP}} 14.0, \mathrm{CH}_{2}\right), 5.0(1 \mathrm{H}, \mathrm{v}$ br s, CH) $7.24-7.25(4 \mathrm{H}, \mathrm{m}, \mathrm{Ph})$, 7.34-7.41 (2H, t, Ph), 7.43-7.50 (4H, m, Ph), 7.52-7.59 (2H, m, $\mathrm{Ph}$ ), 7.84-7.99 (8H, br m, Ph). ${ }^{13} \mathrm{C}\left\{{ }^{1} \mathrm{H}\right\}$ NMR (100.61 MHz, $\left.\mathrm{CDCl}_{3}\right): \delta 28.98\left(\mathrm{~s}, \mathrm{CH}_{3}\right), 33.05\left(\mathrm{t},{ }^{1} J_{\mathrm{CP}} 54.7, \mathrm{CH}\right), 39.81\left(\mathrm{~s}, \mathrm{CH}_{2}\right)$, 127.51 (d, ${ }^{1} J_{\mathrm{CP}} 108.6$, ipso-Ph), 127.85 (d, ${ }^{1} J_{\mathrm{CP}} 107.9$, ipso-Ph), 128.80-129.15 (m, Ph), 129.20-129.15 (m, Ph), 131.00-131.42 (m, Ph), 133.09 (s, Ph), 133.42 (s, Ph), 205.7 (s, C=O). ${ }^{31} \mathrm{P}\left\{{ }^{1} \mathrm{H}\right\}$ NMR (161.98 MHz, $\mathrm{CDCl}_{3}$ ): $\delta 40.3$ (br s, $W_{1 / 2} 0.5$ ).

\subsection{Extraction of f-block elements}

The distribution of $\mathrm{U}(\mathrm{VI}), \mathrm{La}(\mathrm{III}), \mathrm{Nd}(\mathrm{III}), \mathrm{Ho}(\mathrm{III})$, and $\mathrm{Yb}$ (III) in the extraction systems was studied in model solutions of 3.75 $\mathrm{M}$ nitric acid at metal concentrations of $0.25 \mathrm{mM}$. Extractant solutions $(0.01 \mathrm{M})$ in $\mathrm{CHCl}_{3}$ were prepared from precisely weighed amounts of the reagents. The experiments were carried out in ampoules with ground stoppers at $20 \pm 1{ }^{\circ} \mathrm{C}$. The volumes of both organic and aqueous phases were equal to $2 \mathrm{~mL}$. The solution was stirred for $30 \mathrm{~min}$ at $80 \mathrm{rpm}$ to achieve constant values of the distribution ratio $\left(D=[\mathrm{M}]_{\mathrm{org}} /\right.$ $\left.[\mathrm{M}]_{\mathrm{aq}}\right)$. After the extraction, $0.5 \mathrm{~mL}$ of the aqueous solution was taken for further analysis. Metal concentrations in the initial and equilibrated aqueous solutions were determined by spectrophotometry. ${ }^{38}$

\subsection{X-ray crystallography}

The X-ray diffraction data were collected on a Bruker Apex II CCD diffractometer using Mo-K $\alpha(\lambda=0.71073 \AA)$ radiation. The structures were solved by direct methods and refined by fullmatrix least squares against $F^{2}$. Non-hydrogen atoms were refined in anisotropic approximation with an exception of the disordered atoms. The oxygen atoms of the uranyl cation in 2 are equally disordered over two sites and were refined isotropically. Occupation of solvate molecules in 2-5 was refined as a free variable giving full occupation with an exception of one MeCN solvent molecule in 3 which was further fixed at 1/3. Complex 3 crystallizes as a twinned single crystal; twin components were separated using PLATON ${ }^{39}$ and refined using the HKLF 5 instruction and additional BASF factor. Hydrogen atoms were included in the refinement by the riding model with $U_{\text {iso }}(\mathrm{H})=n U_{\text {eq }}(\mathrm{C})$, where $n=1.5$ for methyl and $\mathrm{OH}$ groups and 1.2 for the other atoms. All calculations were performed using SHELXL2013 ${ }^{40}$ and OLEX2.0 ${ }^{41}$ program packages.

CCDC 1442097-1442102 for compounds L and 1-5 contain the supplementary crystallographic data for this study (Table 8).

\subsection{Computational details}

Topological analysis of electron density according to Bader's "Atoms in Molecules" theory (AIM) ${ }^{21}$ was performed using the AIMAll $^{42}$ program. The electron density $\rho(r)$ (ED) in wfx-format for AIM calculations was generated for complexes 1-5 in the GAUSSIAN $09^{43}$ software suite at the DFT level of theory. The hybrid $\mathrm{PBE}^{44}$ functional and all-electron scalar relativistic basis set ${ }^{45}$ for $U$ and La atoms and $6-311+G^{* *}$ basis set $^{46}$ for other atoms were utilized. The geometry parameters were used

Table 8 Crystallographic data and refinement parameters for $L$ and 1-5

\begin{tabular}{|c|c|c|c|c|c|c|}
\hline Compound & L $0.5 \mathrm{C}_{6} \mathrm{H}_{6}$ & 1 & 2 & 3 & 4 & 5 \\
\hline $\begin{array}{l}\text { Empirical } \\
\text { formula }\end{array}$ & $\mathrm{C}_{31} \mathrm{H}_{29} \mathrm{O}_{3} \mathrm{P}_{2}$ & $\mathrm{C}_{28} \mathrm{H}_{26} \mathrm{~N}_{2} \mathrm{O}_{11} \mathrm{P}_{2} \mathrm{U}$ & $\mathrm{C}_{58} \mathrm{H}_{58} \mathrm{~N}_{2} \mathrm{O}_{19} \mathrm{P}_{4} \mathrm{U}_{2}$ & $\mathrm{C}_{60.67} \mathrm{H}_{59} \mathrm{LaN}_{5.33} \mathrm{O}_{15} \mathrm{P}_{4}$ & $\mathrm{C}_{62} \mathrm{H}_{61} \mathrm{~N}_{6} \mathrm{NdO}_{15} \mathrm{P}_{4}$ & $\mathrm{C}_{58} \mathrm{H}_{58} \mathrm{~N}_{3} \mathrm{NdO}_{16} \mathrm{P}_{4}$ \\
\hline Color, habit & $\begin{array}{l}\text { Colorless, } \\
\text { prism }\end{array}$ & Yellow, plate & Yellow, needle & Colorless, needle & Pink, needle & Pink, prism \\
\hline $\begin{array}{l}\text { Crystal size } \\
\left(\mathrm{mm}^{3}\right)\end{array}$ & $\begin{array}{l}0.23 \times 0.18 \times \\
0.15\end{array}$ & $0.23 \times 0.18 \times 0.10$ & $0.29 \times 0.08 \times 0.08$ & $0.29 \times 0.08 \times 0.08$ & $0.31 \times 0.08 \times 0.06$ & $0.23 \times 0.19 \times 0.11$ \\
\hline Space group, $Z$ & Triclinic, $P \overline{1}, 2$ & $\begin{array}{l}\text { Monoclinic, } P 2_{1} / c \text {, } \\
4\end{array}$ & $\begin{array}{l}\text { Orthorhombic, } \\
\text { Pbca, } 4\end{array}$ & Monoclinic, $C 2 / c, 4$ & $\begin{array}{l}\text { Monoclinic, } C 2 / c \text {, } \\
4\end{array}$ & Triclinic, $P \overline{1}, 2$ \\
\hline$a(\AA)$ & $9.8274(12)$ & $11.3280(7)$ & $18.2266(7)$ & $13.444(8)$ & $13.4706(8)$ & $12.590(7)$ \\
\hline$b(\AA)$ & $11.8989(15)$ & $13.8253(9)$ & $17.8372(7)$ & $17.849(9)$ & $17.8919(10)$ & $13.510(10)$ \\
\hline$c(\AA)$ & $13.0901(16)$ & $19.7227(13)$ & $19.0939(8)$ & $26.571(15)$ & $26.4711(15)$ & $19.148(15)$ \\
\hline$\alpha\left({ }^{\circ}\right)$ & $70.615(2)$ & 90 & 90 & 90 & 90 & $90.574(16)$ \\
\hline$\theta_{\max }\left({ }^{\circ}\right)$ & 29.00 & 31.77 & 27.00 & 25.96 & 31.62 & 29.906 \\
\hline$I_{h k l}$ coll/uniq & $16085 / 7124$ & $34749 / 7917$ & $62107 / 6743$ & $11231 / 8846$ & $44834 / 10755$ & 38 088/17 037 \\
\hline$R_{\text {int }}$ & 0.042 & 0.055 & 0.052 & - & 0.027 & 0.145 \\
\hline $\begin{array}{l}\text { Obs. refl./N/ } \\
\text { restraints }\end{array}$ & $5432 / 327 / 0$ & $6105 / 398 / 0$ & $4803 / 406 / 11$ & $4827 / 394 / 14$ & $10078 / 403 / 2$ & $8453 / 752 / 41$ \\
\hline$R,{ }^{a} \%[I>2 \sigma(I)]$ & 0.047 & 0.028 & 0.065 & 0.099 & 0.023 & 0.078 \\
\hline$R_{\mathrm{w}},{ }^{b} \%$ & 0.125 & 0.057 & 0.158 & 0.245 & 0.060 & 0.152 \\
\hline $\mathrm{GOF}^{c}$ & 1.02 & 1.04 & 1.06 & 1.03 & 1.06 & 1.03 \\
\hline
\end{tabular}


as those obtained from X-ray diffraction experiments. Interaction energies were estimated with Espinosa's correlation scheme $E_{\text {cont }}=-1 / 2 V(r) .{ }^{22}$ For paramagnetic ionic complex 5, a simplified procedure was applied by reason of a nonconvergence SCF equation. $\pi$-Stacking energy evaluation was performed for "frozen" ligands in conformations that they adopt in complex 5. This technique was checked by computation for complexes $\mathbf{1}$ and 4. The difference in energies obtained by simplified and complete procedures was not larger than $0.02 \mathrm{kcal} \mathrm{mol}^{-1}$.

\section{Acknowledgements}

This work was supported by the Russian Foundation for Basic Research (Grant No. 14-03-00695-a).

\section{Notes and references}

1 For reviews, see: (a) A. E. V. Gorden, M. A. DeVore and B. A. Maynard, Inorg. Chem., 2013, 52, 3445; (b) E. V. Sharova, O. I. Artyushin and I. L. Odinets, Russ. Chem. Rev., 2014, 83, 95; (c) D. Rosario-Amorin, S. Ouizem, D. A. Dickie, Y. Wen, R. T. Paine, J. Gao, J. K. Grey, A. de Bettencourt-Dias, B. P. Hay and L. H. Delmau, Inorg. Chem., 2013, 52, 3063; (d) P. Tkac, G. F. Vandegrift, G. J. Lumetta and A. V. Gelis, Ind. Eng. Chem. Res., 2012, 51, 10433; (e) S. Tachimori and Y. Morita, in Ion exchange and solvent extraction, ed. B.A. Moyer, CRC Press, 2010, vol. 19, pp. 1-64; $(f)$ V. Manchanda, P.N. Pathak and P.K. Mohapatra, in Ion exchange and solvent extraction, ed. B.A. Moyer, CRC Press, 2010, vol. 19, pp. 66-118; $(g)$ C. Hill, in Ion exchange and solvent extraction, ed. B.A. Moyer, CRC Press, 2010, vol. 19, pp. 119-194; (h) V. A. Babain, in Ion exchange and solvent extraction, ed. B.A. Moyer, CRC Press, 2010, vol. 19, pp. 359-380.

2 A. M. Rozen and B. V. Krupnov, Russ. Chem. Rev., 1996, 65, 973.

3 H. J. Cristau, D. Virieux, J. F. Dozol and H. Rouquette, J. Radioanalyt. Nucl. Chem., 1999, 241, 543.

4 I. V. Smirnov, Radiokhimiya (in Russian), 2007, 49, 44.

5 (a) A. N. Turanov, V. K. Karandashev and N. A. Bondarenko, Radiokhimiya (in Russian), 2007, 49, 55; (b) A. N. Turanov, V. K. Karandashev, A. N. Yarkevich and Z. V. Safronova, Solvent Extr. Ion Exch., 2004, 22, 391; (c) T. Yaita and S. Tachimori, Radiochim. Acta, 1996, 73, 27; (d) A. N. Turanov, V. K. Karandashev, V. E. Baulin, A. N. Yarkevich and S. V. Nosenko, Radiokhimiya (in Russian), 2012, 54, 363; (e) A. N. Turanov, V. K. Karandashev, A. N. Yarkevich and Z. V. Safronova, Radiokhimiya (in Russian), 2011, 53, 264; (f) N. E. Kochetkova, O. E. Kojro, N. P. Nesterova, T. Ya. Medved', M. K. Chmutova, B. F. Myasoedov and M. I. Kabachnik, Radiokhimiya (in Russian), 1986, 28, 338; $(g)$ A. Yu. Shadrin, I. V. Smirnov, R. N. Kiseleva,
N. P. Nesterova, Yu. M. Polikarpov and M. I. Kabachnik, Radiokhimiya (in Russian), 1993, 35, 50.

6 A. M. J. Lees and A. W. G. Platt, Inorg. Chem., 2003, 42, 4673.

7 S. Kannan, N. Rajalakshmi, K. V. Chetty, V. Venugopal and M. G. B. Drew, Polyhedron, 2004, 23, 1527.

8 (a) S. M. Cornet, I. May, M. P. Redmond, A. J. Selvage, C. A. Sharrad and O. Rosnel, Polyhedron, 2009, 28, 363; (b) N. J. Hill, W. Levason, M. C. Popham, G. Reid and M. Webster, Polyhedron, 2002, 21, 445; (c) A. D. Sutton, G. H. John, M. J. Sarsfield, J. C. Renshaw, I. May, L. R. Martin, A. J. Selvage, D. Collison and M. Helliwell, Inorg. Chem., 2004, 43, 5480.

9 P. E. Sues, A. J. Lough and R. H. Morris, Inorg. Chem., 2012, 51, 9322.

10 A. N. Turanov, V. K. Karandashev, G. V. Bodrin, E. I. Goryunov and V. K. Brel, Radiokhimiya (in Russian), 2015, 57, 509.

11 J. B. Conant, J. B. S. Braverman and R. E. Hussey, J. Am. Chem. Soc., 1923, 45, 165.

12 E. I. Goryunov, G. V. Bodrin, I. B. Goryunova, Yu. V. Nelyubina, P. V. Petrovskii, T. V. Strelkova, A. S. Peregudov, A. G. Matveeva, M. P. Passechnik, S. V. Matveev and E. E. Nifant广ev, Russ. Chem. Bull., Int. Ed., 2013, 62, 780.

13 Geometry optimization and normal coordinate analysis for the X-ray conformation of $\mathbf{L}$ were carried out using DFT at PBE level by Priroda 6 program package (2006.08.20) [D.N. Laikov, Chem. Phys. Lett., 1997, 281, 151; D.N. Laikov and Yu. A. Ustynyuk, Russ. Chem. Bull., Int. Ed., 2005, 54, 820; J. P. Perdew, K. Bruke and M. Ernzerhof, Phys. Rev. Lett., 1996, 77, 3865].

14 (a) G. A. Doyle, D. M. L. Goodgame, A. Sinden and D. J. Williams, Chem. Commun., 1993, 1170; (b) G. H. John, I. May, M. J. Sarsfield, H. M. Steele, D. Collison, M. Helliwell and J. D. McKinney, Dalton Trans., 2004, 734; (c) B. T. McGrail, L. S. Pianowski and P. C. Burns, J. Am. Chem. Soc., 2014, 136, 4797.

15 W. D. Wang, A. Bakas and J. H. Espenson, Inorg. Chem., 1995, 34, 6034.

16 S. Wahu, J.-C. Berthet, P. Thuéry, D. Guillaumont, M. Ephritikhine, R. Guillot, G. Cote and C. Bresson, Eur. J. Inorg. Chem., 2012, 3747.

17 I. A. Charushnikova and C. Den Auwer, Russ. J. Coord. Chem., 2004, 30, 546.

18 N. Akbarzadeh-T and T. Kondori, Res. Chem. Intermed., 2015, 41, 845.

19 See for example: (a) P. Charpin, G. Folcher, M. Lance, M. Nierlich and D. Vigner, Acta Crystallogr., Sect. C: Cryst. Struct. Commun., 1985, 41, 1302; (b) B. Masci and P. Thuery, Polyhedron, 2005, 24, 229; (c) G. A. Doyle, D. M. L. Goodgame, A. Sinden and D. J. Williams, Chem. Commun., 1993, 1170; (d) I. M. Aladzheva, O. V. Bykhovskaya, Y. V. Nelyubina, Z. S. Klemenkova, P. V. Petrovskii and I. L. Odinets, Inorg. Chim. Acta, 2011, 373,130 . 
20 L. Huang, B.-Q. Ma, C.-H. Huang, T. C. W. Mak, G.-Q. Yao and G.-X. Xu, J. Coord. Chem., 2001, 54, 95.

21 R. F. W. Bader, Atoms in Molecules. A Quantum Theory, Clarendron Press, Oxford, 1990.

22 (a) E. Espinosa, E. Molins and C. Lecomte, Chem. Phys. Lett., 1998, 285, 170; (b) E. Espinosa, I. Alkorta, I. Rozas, J. Elguero and E. Molins, Chem. Phys. Lett., 2001, 336, 457.

23 For example: (a) A. A. Korlyukov and M. Yu Antipin, Russ. Chem. Rev., 2012, 81, 105; (b) A. A. Korlyukov, Russ. Chem. Rev., 2015, 84, 422; (c) C. Matta and R. J. Boyd, The Quantum Theory of Atoms in Molecules, Wiley-VCH, Weinheim, Germany, 2007; (d) I. V. Glukhov, K. A. Lyssenko, A. A. Korlyukov and M. Yu. Antipin, Faraday Discuss., 2007, 135, 203.

24 J. Overgaard, M. P. Waller, R. Piltz, J. A. Platts, P. Emseis, P. Leverett, P. A. Williams and D. E. Hibbs, J. Phys. Chem. A, 2007, 111, 10123.

25 A. G. Matveeva, Z. A. Starikova, R. R. Aysin, R. S. Skazov, S. V. Matveev, G. I. Timofeeva, M. P. Passechnik and E. E. Nifant'ev, Polyhedron, 2013, 61, 172.

26 R. K. Castellano, F. Diederch and E. A. Mayer, Angew. Chem., Int. Ed., 2003, 42, 1210.

27 See for example: (a) M. B. Jones and A. J. Gaunt, Chem. Rev., 2013, 113, 1137; (b) B. G. Vats, S. Kannan, K. Parvathi, D. K. Maity and M. G. B. Drew, Polyhedron, 2015, 89, 116; A. G. Matveeva, M. S. Grigoriev, T. K. Dvoryanchikova, S. V. Matveev, A. M. Safiulina, O. A. Sinegribova, M. P. Passechnik, I. A. Godovikov, D. A. Tatarinov, V. F. Mironov and I. G. Tananaev, Russ. Chem. Bull., Int. Ed., 2012, 61, 399.

28 (a) A. G. Matveeva, A. S. Peregudov, E. I. Matrosov, Z.A. Starikova, S. V. Matveev and E. E. Nifant'ev, Inorg. Chim. Acta, 2009, 362, 3607; (b) W. Levason, E. H. Newman and M. Webster, Polyhedron, 2000, 19, 2697; (c) M. Bosson, W. Levason, T. Patel, M. C. Popham and M. Webster, Polyhedron, 2001, 20, 2055; (d) A. Bowden, S. J. Coles, M. B. Pitak and A. W. G. Platt, Polyhedron, 2014, 68, 258; (e) A. Bowden, P. N. Horton and A. W. G. Platt, Inorg. Chem., 2011, 50, 2553; (f) N.J. Hill, W. Levason, M.C. Popham, G. Reid and M. Webster, Polyhedron, 2002, 21, 445.

29 See for example: (a) R. Babecki, A. W. G. Platt and J. Fawcett, J. Chem. Soc., Dalton Trans., 1992, 675; (b) B.G. Vats, S. Kannan, I. C. Pius, D. M. Noronha, D. K. Maity and M. G. B. Drew, Polyhedron, 2014, $75,81$.

$30 \mathrm{CH} \cdots \mathrm{O}=\mathrm{C}$ contacts were revealed in the ligand $\mathbf{L}(r(\mathrm{H} \cdots \mathrm{O})=$ 2.4/2.6-2.8 $\AA$ ) for intra- and intermolecular interactions) and uranyl complex $1(r(\mathrm{H} \cdots \mathrm{O})=2.3-3.0 / 2.6-2.7 \AA)$, however, they are much weaker than in complexes 3 and 4 (Fig. S1-S3, ESI $\dagger$ ). Accordingly, the IR spectra of $\mathbf{L}$ and complex 1 display $\nu(\mathrm{C}=\mathrm{O})$ at $1720 \mathrm{~cm}^{-1}$.

31 K. Nakamoto, IR and Raman Spectra of Inorganic and Coordination Compounds, Wiley, New York, 5th edn, 1997, Part B, $432 \mathrm{pp}$.
32 Vibrations of the $\mathrm{C} \equiv \mathrm{N}$ group have a low intensity. Moreover, solvate acetonitrile molecules are poorly retained in the crystal lattice of the studied complexes. Thus, freshly prepared finely crystalline complex 4 when stored in air becomes amorphous over time according to X-ray powder diffraction measurements. The content of MeCN in $\mathbf{3}$ and $\mathbf{4}$ according to elemental analysis data and NMR is lower than that determined from X-ray crystallography.

33 For example, $\mathrm{CN}$ of ytterbium, whose radius is close to that of lutetium, equals to eight in the crystalline complex of akin ligand $\left[\mathrm{Yb}\left(\mathrm{NO}_{3}\right)\left(\mathbf{L}^{\prime}\right)_{3}\right]\left(\mathrm{NO}_{3}\right)_{2} \cdot 2 \mathrm{H}_{2} \mathrm{O} .^{6}$

34 (a) A. Bowden, K. Singh and A. W. G. Platt, Polyhedron, 2012, 42, 30; (b) A. G. Matveeva, T. V. Baulina, Z. A. Starikova, M. S. Grigor'ev, Z. S. Klemenkova, S. V. Matveev, L. A. Leites, R. R. Aysin and E. E. Nifant'ev, Inorg. Chim. Acta, 2012, 384, 266.

35 (a) D. Das, S. Kannan, D. K. Maity and M. G. B. Drew, Inorg. Chem., 2012, 51, 4869; (b) C. Villiers, P. Thuéry and M. Ephritikhine, Polyhedron, 2004, 23, 1613; (c) D. J. McCabe, E. N. Duesler and R. T. Paine, Inorg. Chem., 1985, 24, 4626; (d) S. M. Bowen, E. N. Duesler and R. T. Paine, Inorg. Chim. Acta, 1982, 61, 155.

36 In the spectra of lanthanide nitrate complexes with polydentate bisphosphoryl-containing ligands, the signal of the uncoordinated $\mathrm{P}(\mathrm{O})$ group is usually broadened and slightly shifted downfield relative to the free ligand signal. $^{28 a, 34 b}$.

37 E. N. Tsvetkov, N. A. Bondarenko, I. G. Malakhova and M. I. Kabachnik, Zh. Obshch. Khim. (in Russian), 1985, 55, 11.

38 S. B. Savin, Arsenazo III, Atomizdat, Moscow, 1966, 256 pp. (in Russian).

39 A. L. Spek, Acta Crystallogr., Sect. D: Biol. Crystallogr., 2009, 65, 148.

40 G. M. Sheldrick, Acta Crystallogr., Sect. A: Fundam. Crystallogr., 2008, 64, 112.

41 O. V. Dolomanov, L. J. Bourhis, R. J. Gildea, J. A. K. Howard and H. Puschmann, J. Appl. Crystallogr., 2009, 42, 339.

42 Todd A. Keith, AIMAll (Version 10.05.04), TK Gristmill Software, Overland Park, KS, USA, 2012 <aim.tkgristmill.com>.

43 M. J. Frisch, G. W. Trucks, H. B. Schlegel, G. E. Scuseria, M. A. Robb, J. R. Cheeseman, G. Scalmani, V. Barone, B. Mennucci, G. A. Petersson, H. Nakatsuji, M. Caricato, X. Li, H. P. Hratchian, A. F. Izmaylov, J. Bloino, G. Zheng, J. L. Sonnenberg, M. Hada, M. Ehara, K. Toyota, R. Fukuda, J. Hasegawa, M. Ishida, T. Nakajima, Y. Honda, O. Kitao, H. Nakai, T. Vreven, J. A. Montgomery Jr., J. E. Peralta, F. Ogliaro, M. Bearpark, J. J. Heyd, E. Brothers, K. N. Kudin, V. N. Staroverov, T. Keith, R. Kobayashi, J. Normand, K. Raghavachari, A. Rendell, J. C. Burant, S. S. Iyengar, J. Tomasi, M. Cossi, N. Rega, J. M. Millam, M. Klene, J. E. Knox, J. B. Cross, V. Bakken, C. Adamo, J. Jaramillo, R. Gomperts, R. E. Stratmann, O. Yazyev, A. J. Austin, R. Cammi, C. Pomelli, J. W. Ochterski, R. L. Martin, K. Morokuma, V. G. Zakrzewski, G. A. Voth, 
P. Salvador, J. J. Dannenberg, S. Dapprich, A. D. Daniels, O. Farkas, J. B. Foresman, J. V. Ortiz, J. Cioslowski and D. J. Fox, Gaussian 09, Revision D.01, Gaussian, Inc., Wallingford, CT, 2013.

44 J. P. Perdew, K. Burke and M. Ernzerhof, Phys. Rev. Lett., 1997, 78, 1396.
45 (a) D. A. Pantazis and F. Neese, J. Chem. Theory Comput., 2009, 5, 2229; (b) D. A. Pantazis and F. Neese, J. Chem. Theory Comput., 2011, 7, 677.

46 (a) R. Krishnan, J. S. Binkley, R. Seeger and J. A. Pople, J. Chem. Phys., 1980, 72, 650; (b) A. D. McLean and G. S. Chandler, J. Chem. Phys., 1980, 72, 5639. 